\title{
The Leeds urban heat island and its implications for energy use and thermal comfort
}

\author{
James Parker $^{1 *}$ \\ (1) Leeds Beckett University, Leeds, UK \\ *Corresponding author
}

\begin{abstract}
Urban heat islands are evident throughout the world and may become more problematic in temperate climates as global warming continues. This paper characterizes the urban heat island of Leeds, a city in the temperate maritime climate of the UK. Measured weather data from rural and urban sites have been used to quantify the heat island and to create building simulation weather files for the summer of 2013. These weather files have been used to model the impact on energy consumption and thermal comfort in notional non-domestic and domestic buildings, including a hotel, office, house and apartment. The heat island intensity is found to be greatest at night, with the peak in this data set reaching $5.9^{\circ} \mathrm{C}$ at 20:00 on $2^{\text {nd }}$ August 2013, with an average peak value of $2.3{ }^{\circ} \mathrm{C}$ occurring at the same hour for the case study period. Daytime temperatures were however similar at urban and rural sites. In the notional hotel building, air conditioning costs were increased by up to $40 \%$ due to night-time loads whereas consumption in the notional office was similar in all locations. Air temperature, and especially night-time temperature, increased in the domestic examples by an average of approximately 95 additional hours above $25{ }^{\circ} \mathrm{C}$. This work expands knowledge by characterizing the Leeds urban heat island, demonstrating the importance of rural reference site selection for city regions that span a range of altitude, quantifying the gap in building performance when using regional or city centre weather files, and linking building occupancy patterns to the diurnal profile of the urban heat island.
\end{abstract}

Keywords: Urban heat island, thermal modelling, simulation weather data, overheating

Highlights:

- Characterizes the urban heat island of Leeds and quantifies the intensity at an hourly resolution

- Demonstrates the importance of site topography and altitude when using air temperature data to quantify urban heat island intensity

- Creation of urban building simulation weather files for comparison with those used for regulatory compliance from a rural site

- Identifies the link between building occupancy patterns and the diurnal nature of urban heat islands

\section{INTRODUCTION}

Anthropogenic activities including changes in land use, have resulted in the widely acknowledged phenomenon referred to as the Urban Heat Island (UHI) [1-4]. There is now an extensive body of published research that investigates this phenomenon [5], and explores the causes for the UHI associated with the individual features of a city and its local climate [6]. Although the UK has a temperate maritime climate, that is heating-dominated in terms of building energy use, summer overheating is increasingly observed, especially in larger cities where the UHI effect can be more pronounced [7-11]. The aim of this paper is to characterise the UHI in the city of Leeds and to evaluate its impact on building performance. The objectives 
are therefore to use measured data to characterize the UHI profile, to use the same data to create bespoke building simulation weather files for urban and rural locations, and to quantify the impact of the UHI on building energy and thermal performance using dynamic thermal simulation models.

Building simulation weather files are required to perform dynamic thermal simulations of building performance [12]. Building Regulations often require thermal simulations to be carried out to demonstrate compliance, as is the case in the UK, where a set of weather files are approved for use in these calculations [13]. These approved simulation weather files are also recommended for use in more sophisticated domestic overheating assessment [14]. Due to their regulatory purpose and representation of average climatic conditions, these are the most commonly used weather files for building simulation $[12,15]$. Traditionally these weather files are developed using historical data sets and these data have most often been collected at semirural airfield sites which provide robust continuous datasets $[12,16]$. However, existing work has demonstrated that the weather conditions at these non-urban sites do not reflect the microclimates found in UHI areas $[9,10,17]$. For London, the potential impact of the UHI on building performance has been formally acknowledged, with specific weather files which incorporate an UHI element, now being mandatory for regulatory compliance [18]. However, for all of the other regional files available for regulatory compliance in the UK historical weather has been recorded outside of city centres [13].

The data presented here characterises the UHI intensity within Leeds when compared to rural reference sites. Weather data recorded between May and September 2013 has primarily been used in this analysis. It is data from this period that has been used to create the simulation weather files used in the building models. The primary reason for selecting data from this period relates to the rural site from which historical data is used to create the Leeds weather files for regulatory compliance calculations. This weather station was decommissioned at the end of 2013. However, the simulation weather files based upon this site remain in use. Comparison with data from this site is therefore important as it provides an indication of the performance gap that will manifest. Practitioners continue to use these files to demonstrate compliance with regulations related to energy consumption and overheating $[19,20]$. The case study period selection is discussed further in the methodology section 3. The 2013 Leeds UHI diurnal profile has, however, been compared with data from other years to demonstrate a consistent pattern in the UHI; this comparison is presented at the end of section 4.1 .

Thermal modelling has been used to quantify the impact on thermal comfort in domestic buildings and on energy consumption in non-domestic buildings. Results demonstrate the generic need for UHI adjusted weather files and the potential impact on owners and occupiers if these files are not introduced. This work contributes to knowledge of the UHI in heating dominated climates by: characterizing the Leeds urban heat island; demonstrating the importance of rural reference sites in heat island calculations for city regions that span a range of altitude; quantifying the gap in building performance when using regional or Leeds city centre weather files; and by linking building occupancy patterns to the diurnal profile of the UHI.

\section{LITERATURE REVIEW}

\subsection{The urban heat island phenomenon and UK examples}

Continued urbanisation has led to the phenomenon referred to as the Urban Heat Island (UHI) that has been observed and measured throughout the world [5, 21]. Approximately half of the global population now live in cities and this is projected to exceed $60 \%$ by 2030 [22]. A heat island is manifest when urban areas regularly experience higher temperatures than the 
surrounding rural areas $[4,7]$. The UHI intensity (UHII) is the difference between temperatures within an urban area and those at surrounding rural, semi-rural or semi-urban reference sites [7, 23]. This anthropogenic phenomenon was first observed in the $19^{\text {th }}$ century and the term itself can be traced back to the 1950s [5, 24]. It is therefore well understood at a fundamental level. It is, however, a continued subject of extensive research, largely due to the idiosyncrasies of individual cities and local climates [5, 12]. The open availability of remote sensing data has also led to an increased volume of work in this field of research [6, 25]. It is possible to characterise a UHI and its intensity using either or both surface temperature and air temperature $[5,26,27]$. Surface temperatures can be recorded using remote sensing, including satellite measurements, which can provide rich data sets for large geographical areas. However, using surface temperature to infer air temperature is a non-trivial calculation. Air temperature data allow for analysis of local comfort conditions but require extensive infrastructure to gather data at a high spatial resolution and are therefore resource intensive.

Although there can be higher temperatures during the day, many studies have shown the UHI intensity to be greater during nocturnal hours, which can reduce the potential for buildings to undertake night-time cooling, and hence increase the risk of overheating [7, 28-32]. Typically, during daytime hours, air temperature can be similar within urban areas to those at rural reference sites, although surface temperatures are likely to be higher. However, during nocturnal hours, both air temperature and surface temperature in the urban areas are most likely to be higher [7, 33-36]. This is due to the heat from solar radiation being stored within the thermal mass of the built environment (including buildings, roads and other constructions), along with the heat gains associated with human activity [7].

There are numerous factors that contribute to the UHI intensity, with meteorological factors having a significant influence; low wind speed has been shown to correlate with greater UHI intensity and the extent of cloud cover has also been shown as significant (a feature that reduces exposure to direct solar irradiation as well) [37-39]. Changes in landcover are another significant factor that lead to UHIs, with manufactured materials generally having a low albedo and large amounts of thermal mass which lead to increased thermal storage within the city, in comparison with natural materials which can heat up and cool down more efficiently via evapotranspiration [21, 37]. Other factors that influence UHIs include: the urban canopy and boundary layers that can work together to reduce natural cooling effects; moisture and rainfall levels; topography; geometric properties of city architecture; the sprawl and scale of modern cities; and increased sources of urban anthropogenic heat [21].

Urban heat islands have been associated with heat stress and are shown to adversely affect the health of citizens [40-43]. The relationship between higher external temperature and heatrelated health risk is well established, leading to conditions such as heat rash and heat cramps, heat exhaustion, heat stroke, and it can also lead to death [40]. Higher temperatures within UHI areas can also exacerbate pre-existing conditions such as cardiovascular disease [40]. As cities continue to grow and global temperatures increase, heat-related health risks are projected to rise further [40, 44-46]. Other consequences associated with UHIs identified by [47, 48] and summarised in [21] include: increased cooling energy consumption (and cost); increased peak energy demand; increased risk of smog and poor air quality; increased heat stress for citizens; and adverse effects on urban ecosystems. Urban heat islands can, in some instances, be beneficial, for example, they can reduce heating energy consumption during colder months [49, 50]. Additionally, in some cities in extremely arid locations, the geometry and urban green space has been observed to lead to a cool island within a hot, dry climate [42]. However, in most cases, UHIs are associated with the range of problems noted above. 
For cities with a population of one million or more, UHI areas are on average between $1{ }^{\circ} \mathrm{C}$ and $3{ }^{\circ} \mathrm{C}$ warmer than their surrounding countryside [50]. A significant proportion of UHI research has taken place in large cities in the Americas and Asia, where there are extreme, hot climates. Seasonal and hourly analysis of New York's historical heat island shows nocturnal UHI intensity of between $3{ }^{\circ} \mathrm{C}$ to $5{ }^{\circ} \mathrm{C}$, but which falls to approximately zero, or negative values during the middle of the day [51]. Studies of major Chinese cities such as Shanghai and Beijing have also shown a similar pattern between night and day, with higher average UHI intensity overnight, with a nocturnal peak reported for Beijing of $8{ }^{\circ} \mathrm{C}[28,52]$. A range of UHI data for European cities are succinctly summarised by Santamouris [53] which notes: a mean intensity of $2.5^{\circ} \mathrm{C}$ and a peak of $3.5^{\circ} \mathrm{C}$ in Lisbon; peak intensities of $7.5^{\circ} \mathrm{C}$ and $7.3{ }^{\circ} \mathrm{C}$ in Averio and Oporto respectively; between $2{ }^{\circ} \mathrm{C}$ and $5{ }^{\circ} \mathrm{C}$ in Rome; an average value of $1.4^{\circ} \mathrm{C}$ in Parma; a peak intensity of $8{ }^{\circ} \mathrm{C}$ in Barcelona; and a maximum peak of $16{ }^{\circ} \mathrm{C}$ in Athens. Many of the studies referenced by [53] note the prevalence of peaks occurring during nocturnal hours.

Studies carried out in the UK have also noted the UHI to be a predominantly night-time problem $[7,11,17,38,54]$. As previously mentioned, the extent of the UHI for London is such that building simulation weather files have already been published to account for its effects [18]. The UHI in London has been described in multiple publications, Kolokotroni et al [55] present a summary of measured data, with summertime intensity reaching peaks of over $8{ }^{\circ} \mathrm{C}$ during the night, the daily mean value being $2{ }^{\circ} \mathrm{C}$ during the day, and $3.2^{\circ} \mathrm{C}$ during the night $[56,57]$. The wintertime UHI intensity is also significant and can reach peaks of approximately $3{ }^{\circ} \mathrm{C}$ during nocturnal hours [49]. Long-term analysis has been completed for Manchester, which also has a peak summertime intensity of $8^{\circ} \mathrm{C}$ [7]. The diurnal pattern of UHI intensity in Manchester displays large swings in temperature difference, with negative values during the morning hours and much higher values overnight [54]. A significant UHI has also been measured for Birmingham through combined remote sensing and high-resolution air temperature data, showing peaks in excess of $7{ }^{\circ} \mathrm{C}[58,59]$.

Building performance can be strongly influenced by the UHI, a meta-analysis identified an increase in peak electricity demand of between $0.45 \%$ and $4.6 \%$ per degree of UHI intensity, and an increase in overall consumption of between $0.5 \%$ and $8.5 \%$ per degree [60]. Specific examples in this work show percentage increases per degree of UHI intensity ranging from $0.5 \%$ in the Netherlands up to $8.5 \%$ in the USA [60]. The UHI in Rome has been estimated to increase cooling energy demand by $30 \%$ [50] and a study in Beijing found an approximate increase in cooling energy of $11 \%$ [28]. The London UHI has been shown to increase cooling loads by approximately $25 \%$ but also to reduce annual heating consumption by approximately $22 \%$ when compared with semi-rural sites [55, 57]. A specific study of office buildings for London demonstrated an increase of $16 \%$ in cooling energy demand compared with a rural site; however, differences in performance were directly related to the design of the buildings, with greater differences estimated for optimised designs [55]. In addition to increasing overall cooling energy demand, UHI conditions can reduce the efficiency of air conditioning systems by approximately $25 \%$ as well [53].

The impact of UHI intensity on thermal comfort has also been evaluated in modelling studies. Simulations of different domestic archetypes within London estimated the UHI to increase indoor temperatures by an average of between $1{ }^{\circ} \mathrm{C}$ and $1.5^{\circ} \mathrm{C}$, with a mean value of $1.4{ }^{\circ} \mathrm{C}$, although this was as high as $4.4^{\circ} \mathrm{C}$ in certain cases [10]. This study also noted that over-shading and night-time ventilation have a significant impact on this [10]. The impact of the London UHI on office buildings has also been modelled, with increases in the percentage of occupied hours above $28{ }^{\circ} \mathrm{C}$ correlating with proximity to the centre of the city [42]. Modelling of a typical house in Manchester estimated a $3{ }^{\circ} \mathrm{C}$ rise in internal temperatures and a $60 \%$ rise in discomfort 
hours due to the UHI effect [61]. It is important to note that the vast majority of domestic properties in the UK are naturally ventilated which means thermal comfort is directly linked to external conditions [62].

\subsection{Building simulation weather data}

To be used in dynamic thermal simulations, weather files need to include hourly data for: dry bulb, wet bulb and dew point temperature; global, direct and diffuse solar radiation; wind speed and wind direction; barometric pressure; relative humidity; and cloud cover [12]. The relative importance of data collection locations has been demonstrated in existing work focused on overheating [63]. The most common type of weather files are created to represent typical conditions using observed data, either by using a twelve month period considered representative of average conditions, or a composite file of typical individual months [12]. These files are described as Test Reference Year (TRY) files in the UK, with other regions having specific versions, for instance Typical Meteorological Year (TMY) files in the USA; International Weather for Energy Calculations (IWEC) files that cover worldwide locations are published by the American Society of Heating, Refrigerating and Air-Conditioning Engineers (ASHRAE) and aim to unify global weather data [12]. Similar methodologies are employed to produce files for more extreme conditions, such as Design Summer Year (DSY) files in the UK [12]. Although there are limitations to these approaches [12], these do not apply to the files used in this work, as they are based upon measured data for a specific period and do not attempt to replicate typical conditions.

It is also possible to create weather files using synthetic weather produced using weather generators, of which there are many examples [12]. Existing work has focused on producing files by adjusting existing data sets to reflect calculated UHI conditions [7, 54, 64-66]. Of particular note in the context of this paper is a technique developed to generate files for the UK that can account for the UHI intensity [66]. Historical data were analysed for the twenty-one major towns and cities to produce monthly, seasonal and annual mean UHI intensity; for Leeds the annual mean is estimated at $0.7^{\circ} \mathrm{C}$, with peaks of $0.8^{\circ} \mathrm{C}$ mainly in the summer months [66]. This methodology then uses typical diurnal UHI profiles to downscale the monthly data to produce weather files [66]. As already noted, existing research has led to the release of UHI specific files for central London [18]. Much work has also been completed in Manchester, with adjustments published to account for the UHI, both for existing and future climate scenarios [7, 54]. It is also pertinent to note that the long-term monitoring in Manchester shows that the UHI intensity is increasing as the city develops [7, 54].

Further to the literature reviewed here, this research aims to address gaps in the existing knowledge. Primarily, the UHI in Leeds will be characterized in terms of peak intensity and its diurnal profile. Methods to achieve this are not novel to this paper and align with those widely noted in the literature $[7,23,51,53]$, the novelty is associated with the specific city rather than the approach. This work also considers the influence of the rural reference sites and their topography in the UHI calculations; the altitude of sites to the north of Leeds is significantly higher than surrounding areas. This is not something that is relevant to the UK cities considered in existing publications [7, 17, 38, 49,54]. A study of Birmingham does note the influence of altitude on surface temperature stability, but not in the context of a rural reference site used in UHI characterization [58].

Actual year weather data were used to create building simulation weather files for the urban sites which allow the impact of the UHI to be modelled. This is useful as the actual year files capture the peaks and extremes of the UHI as opposed to files created to represent typical conditions, where weather data is morphed to represent current and future scenarios $[10,61$, 
64, 66]. Finally, in an extension to the literature reviewed here, this work also considers the impact of the Leeds UHI in the context of occupancy patterns, including dwellings where occupants use different zones at different times, an office which operates during working hours and a hotel which operates over 24 hours but has increased occupancy during the night. Previous work has noted the impact on domestic night-time comfort [10,61] and night-time purge ventilation strategies [55] but not specifically non-domestic buildings with increased night-time occupancy like the hotel example used here.

\section{METHODOLOGY}

During 2013 the UK experienced a significant heatwave for most of July, which was the third hottest on record [67]. It is data collected between May and September 2013 that have been used to create the building simulation weather files used in this work. In contemporary overheating analysis, such as that defined in the CIBSE TM59 methodology, it is the period from May to September that is used to quantify the extent of overheating [14]. It is common for high-pressure weather systems to dominate the UK climate at the beginning of May, along with low wind speeds which can exacerbate the UHI intensity [37, 39, 68]. As described in the introduction, 2013 also represents the final year that hourly weather data was recorded for the Leeds East Airport (LEA) site noted in Table 1. This is important as it is historical data from this site that is used to create the TRY and DSY building simulation weather files for Leeds that are approved for use in UK regulatory compliance calculations [13, 69]. It is therefore comparison between modelled results from the LEA weather file with those from the urban sites that provides the strongest indication of the performance gap that is most likely to manifest in practice. Currently, the only commercially available building simulation weather files for Leeds are for either the LEA site or the Leeds Bradford Airport (LBA) site, both in rural locations $[13,70]$. It was the combined availability of data from the LEA site and the significant heatwave noted above that led to the selection of the 2013 data sets for this study.

There were three stages required to characterise the UHI and to model its impact on building performance. The first stage was to quantify the UHI in Leeds; this was done primarily for the summer of 2013 using data sets that recorded air temperature, relative humidity, solar radiation, wind speed and direction. The characterised UHI for 2013 was then compared with UHI patterns for 2017, 2018 and 2019 to demonstrate the consistency of the UHI characteristics in Leeds, and that the UHI during 2013 was not an isolated phenomenon. The second stage was to create localised building simulation weather files and the final stage was to use these files to quantify the impact of the UHI using dynamic thermal simulations of notional buildings.

In order to characterise the UHI, it is necessary to compare air temperature data collected at rural reference sites with those from the urban environment [23]. In total, five data sets were used in this work, three from the city centre area of Leeds and two from non-urban, semi-rural sites. As weather conditions are a crucial variable in the safe operation of aircraft, automated weather stations have traditionally been located at airfields. The two non-urban reference sites used in this work are both located at airfields. Leeds Bradford Airport (LBA) is a commercial airport located to the North-West of the city, the second is a private airport, Leeds East Airport (LEA), located near to the village of Church Fenton to the East of the city. Data for the urban locations was collected at the University of Leeds (UOL) by the National Centre for Atmospheric Science, at Leeds Beckett University by the Leeds Sustainability Institute and at a site in Knowsthorpe Gate by Leeds City Council (LCC). Table 1 provides details of the weather stations and the map shown in Fig. 1 shows the relative location of each weather station. 
Table 1. Weather data sources and station locations

\begin{tabular}{llclll}
\hline Ref. & Location & Co-ordinates & Elevation & Source & Data period \\
\hline LBA & $\begin{array}{l}\text { Leeds Bradford } \\
\text { Airport }\end{array}$ & $53.87,-1.66$ & $205 \mathrm{~m}$ & $\begin{array}{l}\text { National Centers for } \\
\text { Environmental Information }\end{array}$ & $\begin{array}{l}\text { May-September 2013 } \\
2017-2019\end{array}$ \\
\hline LEA & $\begin{array}{l}\text { Leeds East } \\
\text { Airport }\end{array}$ & $53.83,-1.94$ & $11 \mathrm{~m}$ & $\begin{array}{l}\text { National Centers for } \\
\text { Environmental Information }\end{array}$ & May-September 2013 \\
\hline UOL & $\begin{array}{l}\text { University of } \\
\text { Leeds }\end{array}$ & $53.81,-1.56$ & $96 \mathrm{~m}$ & $\begin{array}{l}\text { National Centre for } \\
\text { Atmospheric Science }\end{array}$ & May-September 2013 \\
\hline LCC & $\begin{array}{l}\text { Knowsthorpe } \\
\text { Gate }\end{array}$ & $53.78,-1.51$ & $31 \mathrm{~m}$ & Leeds City Council & May-September 2013 \\
\hline LBU & $\begin{array}{l}\text { Leeds Beckett } \\
\text { University }\end{array}$ & $53.80,-1.54$ & $61 \mathrm{~m}$ & $\begin{array}{l}\text { Leeds Sustainability } \\
\text { Institute }\end{array}$ & $\begin{array}{l}\text { May-September } \\
2017-2019\end{array}$ \\
\hline
\end{tabular}

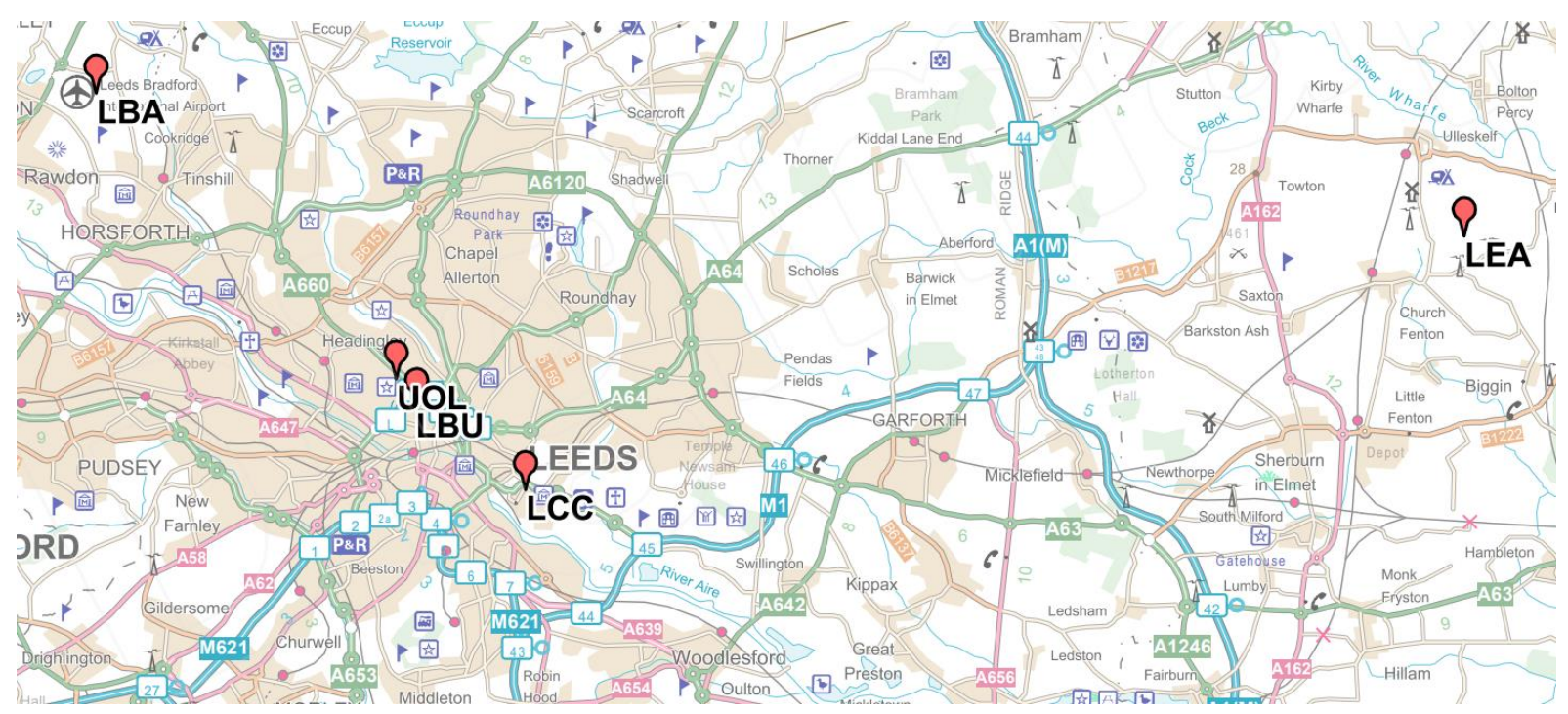

Fig. 1. Relative location of weather stations (Contains OS data $@$ Crown copyright and database rights 2020 Ordnance Survey [100025252])

The data set from Leeds Beckett University (LBU) began in 2015 and only air temperature data were used to compare the characterisation of the Leeds UHI during 2013 with the UHI intensity during May to September in the years 2017 - 2019; to reiterate, this was to demonstrate the enduring nature of the Leeds UHI and to show that the UHI during 2013 was not an isolated event. All data were recorded at hourly intervals apart for the UOL data which was recorded at 5-minute intervals. An average for each hour was calculated from the raw data which meant that most missing data was accounted for in this process. However, there were some missing hourly values for wind speed and direction. In total, there were 3672 hours between May and September. There were 16 missing values for wind speed $(0.004 \%)$ which were replaced using linear interpolation. In the wind direction data, there were 391 missing values $(10.6 \%)$; of these, $141(3.8 \%)$ were replaced using linear interpolation. The remaining 250 values $(6.8 \%)$ which were in groups, were replaced using the LCC data which is the nearest reference site. The LCC data set had 19 missing air temperature values $(0.005 \%)$ that were replaced using linear interpolation.

To quantify and characterise the UHI intensity, the difference between the urban and rural air temperature was calculated at hourly intervals. This was first done using the average 
temperature of the urban and rural sites. However, a second approach was used to help illustrate the importance of location and topography when evaluating UHI intensity. The relationship between altitude and a gradual decrease in air temperature is well established in climatology [30]. As can be seen in Table 1, the LBA site is at a significantly higher elevation than the other rural reference site, LEA. It also experiences higher wind speeds than the city centre as illustrated in Fig. 2, which compares wind speeds from the LBA site with those from the LEA, UOL and LCC sites. The sites at higher elevations have the higher wind speeds, with average wind speeds for the entire period of $9.5 \mathrm{~m} / \mathrm{s}$ at the LBA site (rural, $203 \mathrm{~m}$ above sea level), 6.2 $\mathrm{m} / \mathrm{s}$ at the UOL site (urban, $96 \mathrm{~m}$ above sea level), $3.9 \mathrm{~m} / \mathrm{s}$ at the LEA site (rural, $11 \mathrm{~m}$ above sea level) and $3.3 \mathrm{~m} / \mathrm{s}$ at the LCC site (rural, $31 \mathrm{~m}$ above sea level).

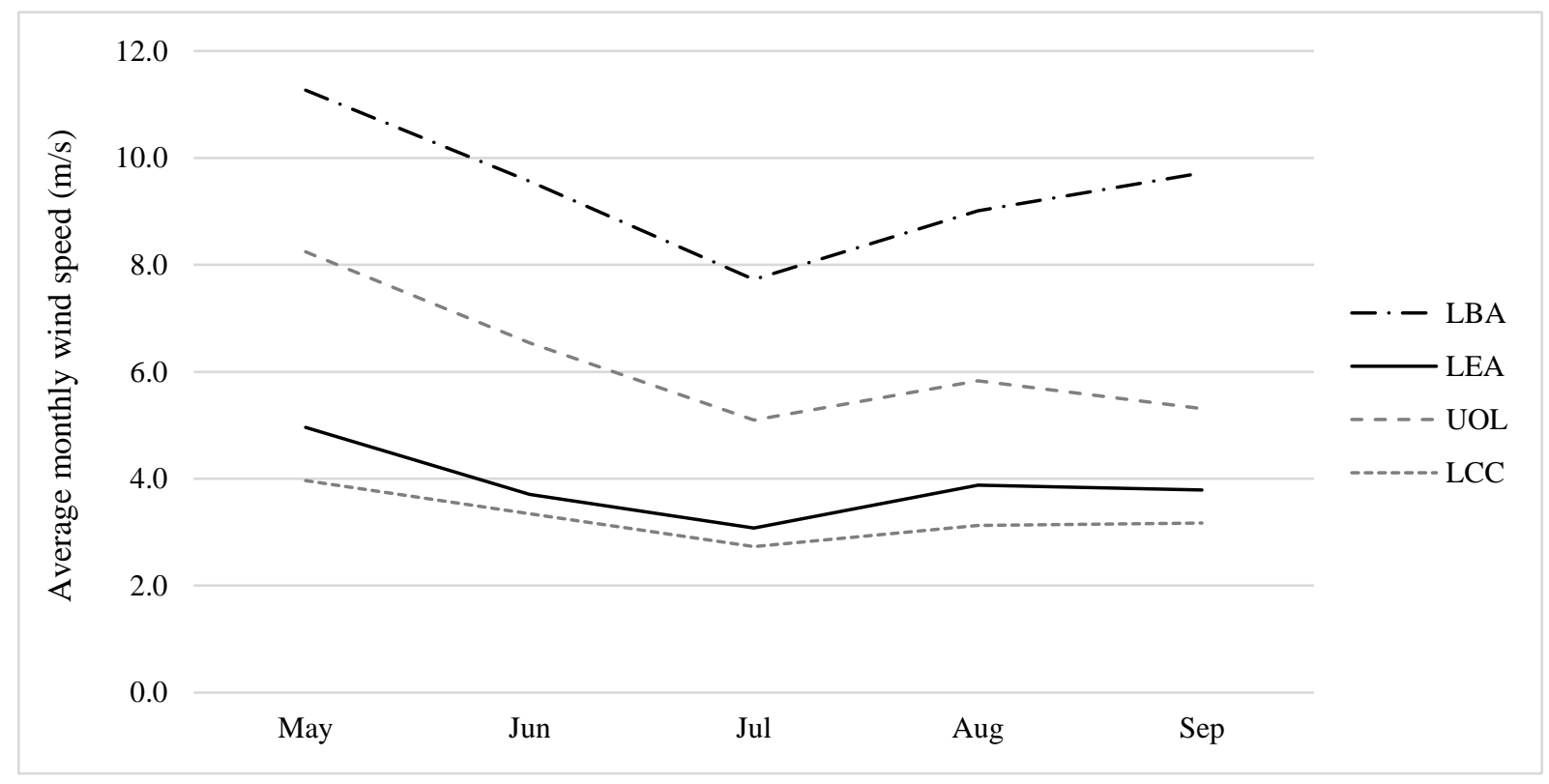

Fig. 2. Comparison of average monthly wind speeds at weather station sites.

The higher altitude and wind speeds at LBA are therefore likely to result in lower temperatures than those at the other sites; evidence of this is presented in section 4.1 of this paper. The second comparison therefore calculates the difference between the urban sites and the LEA site only. As already noted, weather data collected at the LEA site are used to demonstrate regulatory compliance for non-domestic buildings in the UK $[13,71]$. In practice this can lead to gaps in performance, with micro-climates known to be one of the contributors to differences between modelled and measured performance [72].

\subsection{Simulation weather data}

In order to model the impact of the Leeds UHI, it was necessary to create building simulation weather files that are representative of conditions within the city centre. The range and resolution of input variables are the reasons that creating bespoke simulation weather files for specific locations is a non-trivial task. As data from the LEA site is used for regulatory compliance [13], this site was used as the primary rural reference point. Actual year weather files processed by White Box Technologies for the LBA and LEA sites were used in this work [70]. These files are created using the IWEC2 methodology and use data from the National Centers for Environmental Information [70, 73]. 
In total, four weather files were used to simulate building performance, the two non-urban files being those from the LBA and LEA sites. The UOL and LCC data were used to create the weather files that reflect the Leeds UHI. Fig. 2 shows that the average wind speeds at the UOL site are significantly faster than those at the LCC site. Despite this, there is a strong correlation between the air temperature and global solar radiation at the two sites as can be seen in Fig. 3 .

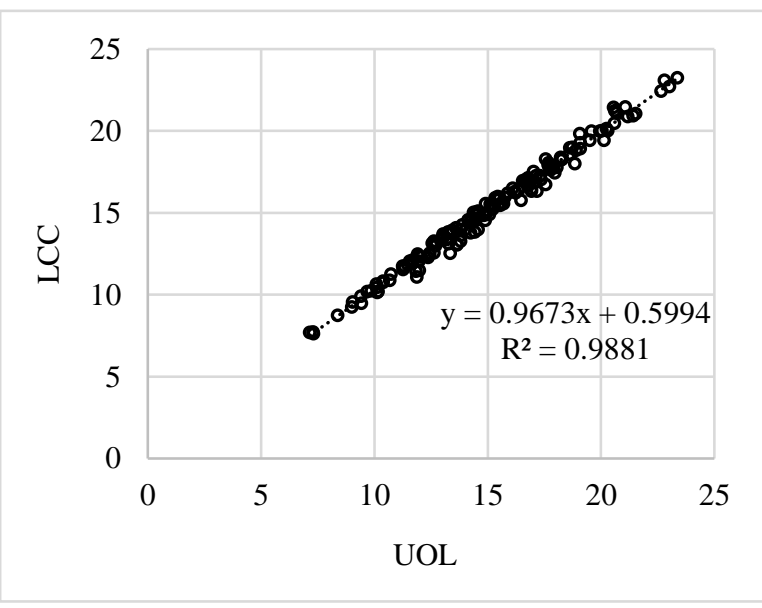

(a) Air temperature $\left({ }^{\circ} \mathrm{C}\right)$

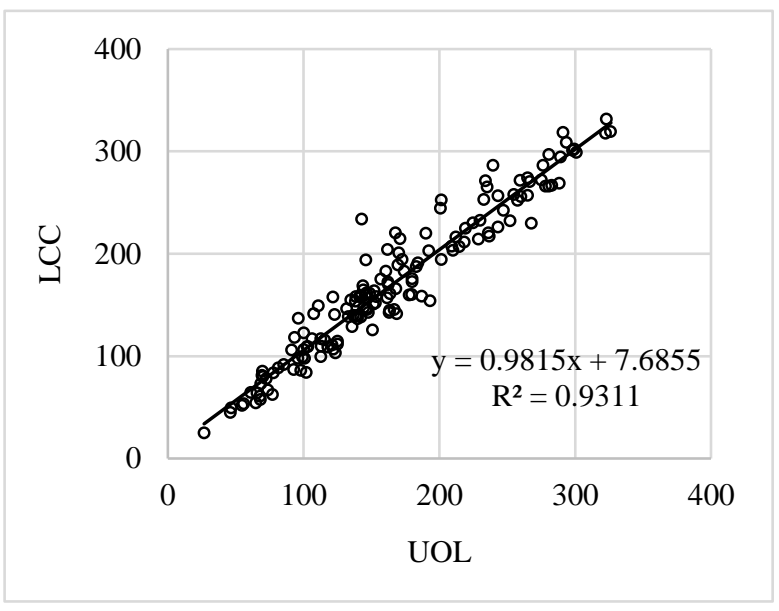

(b) Global solar radiation $\left(\mathrm{W} / \mathrm{m}^{2}\right)$

Fig. 3. Relationship of daily average air temperature (a) and global solar radiation (b) between two urban sites.

\subsection{Case study buildings}

Four indicative building models were created to demonstrate the impact on building performance. Although these are notional buildings, they are all based upon either existing or proposed buildings in Leeds. The two non-domestic buildings used are a relatively low-rise solid wall office building and a relatively modern medium-rise city centre hotel with metal cladding. These were selected due to their different construction types but also due to their occupancy patterns. As the case study buildings are in urban areas, two versions of each model were produced to account for the shading effects of surrounding buildings (referred to here as 'urban shading.'). The first versions of the models do not include any surrounding buildings as they will not always be over-shaded in reality; the second version of the buildings account for the impact of urban shading from the surrounding buildings. In each instance, the surrounding buildings are assumed to be the same height as the case study building on all orientations, and are set back at $9 \mathrm{~m}$ to include space for surrounding roads. In reality, the level of shading for buildings of this nature will depend entirely on their location. For example, the office used here is based upon a building that has a small park on its north façade but is surrounded by buildings of a similar height on all other elevations; the terraced house is also surrounded by similar buildings. In contrast to this, both the existing hotel building and the proposed apartment block are almost completely unshaded on all but their northern façade. The models in this study are intended to provide indicative results and present two extremes, with no urban shading and urban shading on all sides; real values are likely to fall within these bounds. This represents an area for further work and is discussed in section 5.

Both non-domestic buildings use Variable Air Volume (VAV) mechanical ventilation with air cooled chillers. The occupancy patterns and internal heat gains follow those specified within 
the National Calculation Method (NCM) which defines model inputs for regulatory compliance calculation in the UK [71]. The domestic buildings are a solid-wall mid-terraced building (typical of historical housing stock in Leeds) and a modern well insulated one-bedroom apartment; this is a mid-floor apartment and therefore only includes U-values for external walls, the surrounding spaces are treated as being adiabatic in terms of heat exchange. Neighbouring dwellings are treated as adiabatic as it is assumed that occupancy patterns will be similar to those in the case study dwellings, and that there is zero conductive heat exchange through any party walls. Even if there were differing occupancy patterns in neighbouring dwellings, the impact of any conductive heat transfer driven by this would be negligible as it is the outside air temperature and wind speed that are the dominating variables in terms of overheating. The terrace house has a cellar and a room in the roof following a loft conversion. The occupancy patterns and internal heat gains follow those specified within TM59 for use in dynamic overheating assessments [14].

Model images of the four buildings are shown in Fig. 4, illustrating the form of the case study models (a) and the location of the surrounding buildings in the models that include urban shading (b). The key inputs for the buildings are summarised in Table 2. All buildings were modelled in DesignBuilder software which uses the EnergyPlus physics engine [74]. The energy consumption for air-conditioning was used to quantify the impact on non-domestic performance and differences between internal air temperature were used to evaluate the domestic building performance [14].

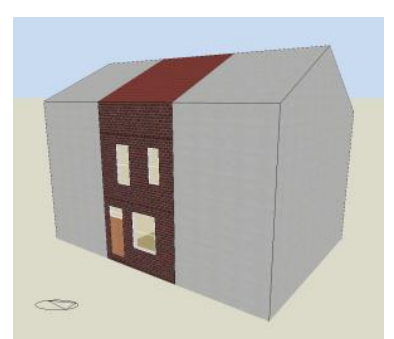

(i) House

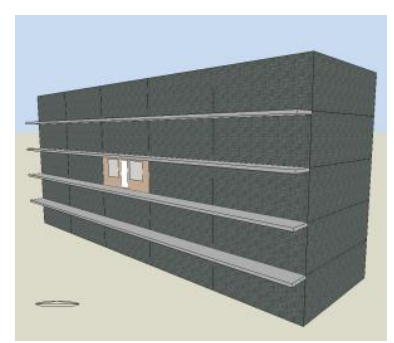

(ii) Apartment

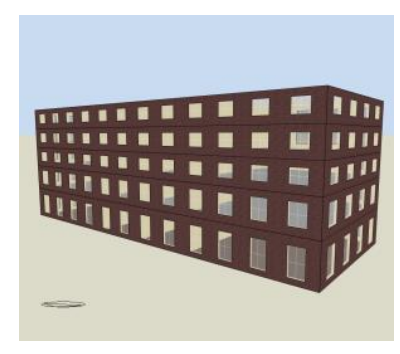

(iii) Office

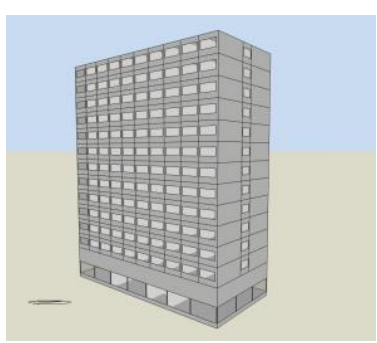

(iv) Hotel

(a) Case study building form

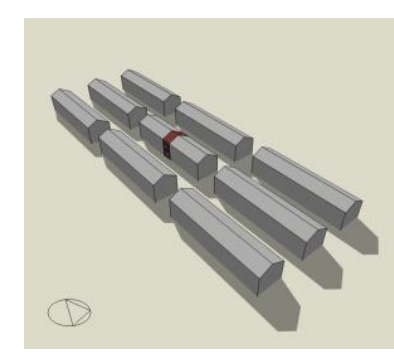

(i) House

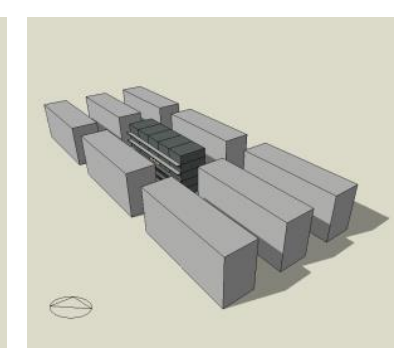

(ii) Apartment

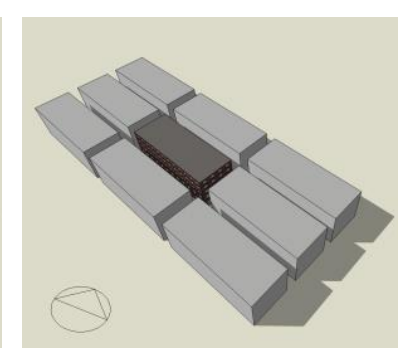

(iii) Office

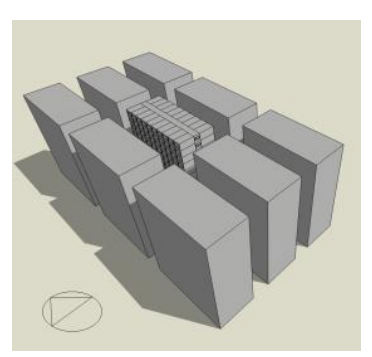

(iv) Hotel

(b) Case study models including urban shading form surrounding buildings

Fig. 4. Model visualisations of the four notional case study buildings 
Table 2. Summary of model inputs for notional buildings

\begin{tabular}{|c|c|c|c|c|}
\hline Input & Office & Hotel & Apartment & House \\
\hline Total floor area $\left(\mathrm{m}^{2}\right)$ & 7,292 & 8,940 & 55 & 81 \\
\hline Building height (m) & 23 & 49 & 3 & 11 \\
\hline Storeys & 5 & 13 & 1 & 3 \\
\hline Orientation (front façade) & South-West & West & South & North-East \\
\hline Infiltration $\left(\mathrm{m}^{3} / \mathrm{h} / \mathrm{m}^{2} @ 50 \mathrm{~Pa}\right)$ & 12.0 & 10.0 & 1.5 & 15.0 \\
\hline Wall U-value $\left(\mathrm{W} / \mathrm{m}^{2} \cdot \mathrm{K}\right)$ & 1.498 & 0.260 & 0.166 & 2.084 \\
\hline Ground floor U-value $\left(\mathrm{W} / \mathrm{m}^{2} \cdot \mathrm{K}\right)$ & 1.463 & 1.458 & N/A & 0.350 \\
\hline Roof U-value $\left(\mathrm{W} / \mathrm{m}^{2 \cdot} \mathrm{K}\right)$ & 0.346 & 0.179 & N/A & 0.372 \\
\hline Window U-value $\left(\mathrm{W} / \mathrm{m}^{2} \cdot \mathrm{K}\right)$ & 1.978 & 1.600 & 0.786 & 2.708 \\
\hline Window-wall ratio (\%) & 25 & 28 & 18 & 9 \\
\hline Cooling set point $\left({ }^{\circ} \mathrm{C}\right)$ & $24{ }^{\circ} \mathrm{C}$ & $25^{\circ} \mathrm{C}$ & $25^{\circ} \mathrm{C}$ & $25^{\circ} \mathrm{C}$ \\
\hline Air conditioning CoP & 1.8 & 1.8 & N/A & N/A \\
\hline Window opening (\% of area) & N/A & N/A & 40 & 40 \\
\hline Occupancy \& heat gains & $\mathrm{NCM}$ - Office & NCM - Hotel & TM59 & TM59 \\
\hline Shading from building form & None & None & $\begin{array}{c}1.5 \mathrm{~m} \text { balcony } \\
\text { overhang }\end{array}$ & $\begin{array}{l}\text { Adjacent } \\
\text { dwellings }\end{array}$ \\
\hline
\end{tabular}

\section{RESULTS}

\subsection{Leeds urban heat island characteristics}

Data from 2013 show that the UHI in Leeds is comparable with many other examples reported in the literature, with nocturnal temperatures significantly higher in the city than at the rural reference sites. The charts in Fig. 5 illustrate the average diurnal temperature profiles for the full case study period and for July. Comparison of the two charts shows the difference between the temperature profiles is influenced by the lower temperatures at the LBA site. When the urban sites are compared with the LEA site (Chart b), the differences are less pronounced.

In keeping with examples from the literature, when comparing the temperature with the LEA site only, daytime temperatures in the urban and rural location are similar, it is during nocturnal hours that the differences become more distinct. Across the full case study period, average temperatures were $13.3^{\circ} \mathrm{C}$ at the LBA site, $14.6{ }^{\circ} \mathrm{C}$ at the LEA site, $15.1{ }^{\circ} \mathrm{C}$ at the UOL site and $15.2^{\circ} \mathrm{C}$ at the LCC site. The lower average temperature at the LBA site is indicative of the higher wind speeds and elevation of the site. Peak temperature at the LBA site was $27.2^{\circ} \mathrm{C}$, peaks at the other sites were similar, with $30.2{ }^{\circ} \mathrm{C}$ at the LCC site, $30.4{ }^{\circ} \mathrm{C}$ at the UOL site and 
30.6 at the LEA site. This is also in agreement with the literature, with numerous examples reporting higher day time temperatures at the rural refence sites [51, 53, 54].

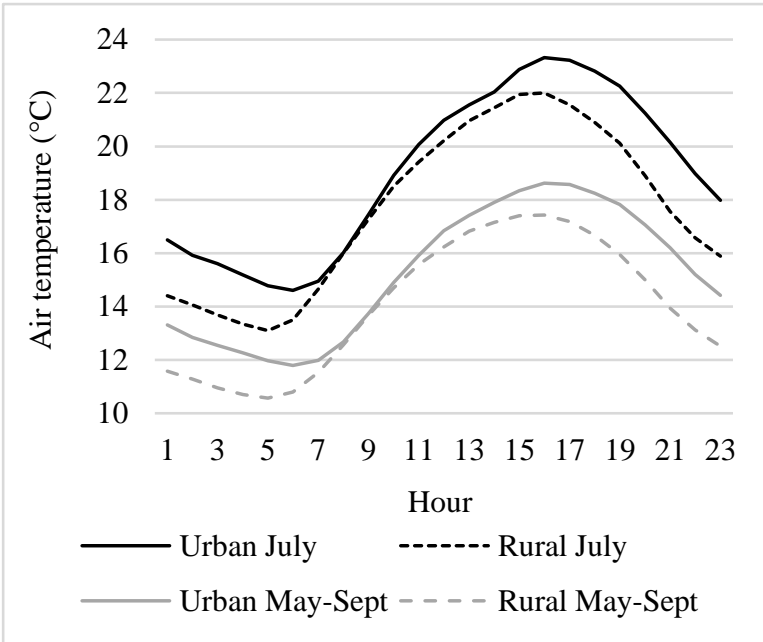

(a) All urban and rural reference sites

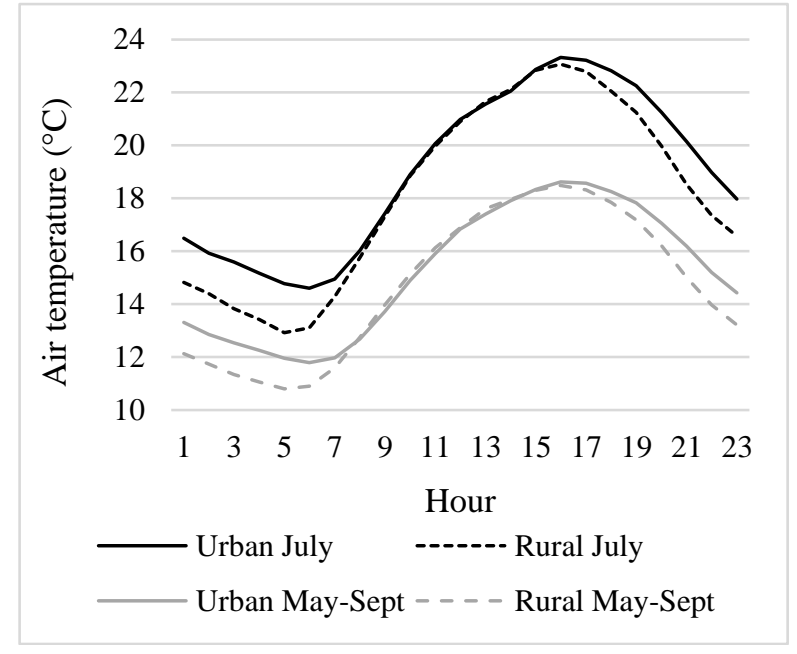

(b) LEA rural reference site only

Fig. 5. Average air temperature diurnal profiles for July and May-September.

Diurnal profiles for the Leeds UHII are shown in Fig. 6. Both charts show the average daily profile and profiles for the days with the peak mean UHII (peak day, $13^{\text {th }}$ June 2013) and the peak hourly UHII (peak hour at 20:00 $2^{\text {nd }}$ August 2013). Data visualised in Fig. 6 also show an agreement with UHII values found in the literature. For both comparisons, there is a higher nocturnal UHII than in the daytime. Using both rural refence sites to calculate the UHII results in an average peak intensity of $2.3{ }^{\circ} \mathrm{C}$ which occurs at 20:00; this reduces to $1.2{ }^{\circ} \mathrm{C}$ at $02: 00$ when using only the LEA site as the rural reference. The mean daily UHII for the period using the two reference sites is $1.2{ }^{\circ} \mathrm{C}$, which reduces to $0.6^{\circ} \mathrm{C}$ when compared with the LEA site only. The mean value of $0.6{ }^{\circ} \mathrm{C}$ is similar to the modelled value for Leeds of $0.7{ }^{\circ} \mathrm{C}$ which is reported in the literature [66]. The peak UHII of $5.9^{\circ} \mathrm{C}$ in Leeds is slightly lower than those recorded in London $\left(8{ }^{\circ} \mathrm{C}\right)$, Manchester $\left(8^{\circ} \mathrm{C}\right)$ and Birmingham $\left(7^{\circ} \mathrm{C}\right)[7,56,58]$. Although still significant, the peak UHII when using only the LEA reference site reduces to $4.8^{\circ} \mathrm{C}$. The charts in Fig. 7 illustrate the distribution of hours across a range of UHII values; the term 'versus' has been used in the chart subtitle as an abbreviated term to describe the comparison of urban sites against rural sites. These again emphasise the impact of including data from the elevated LBA site in the UHII calculation, and also the balance of similar temperatures between the urban and LEA sites that occur during the daytime. 


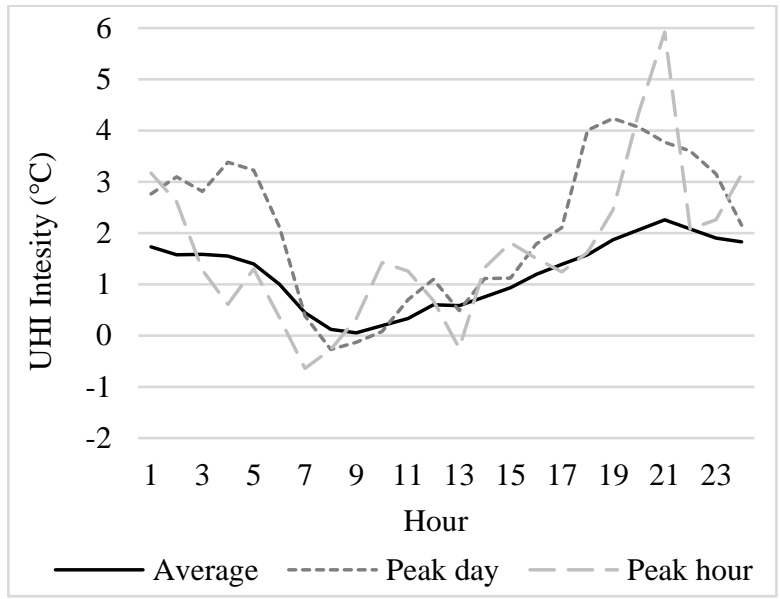

(a) UHII versus all rural sites

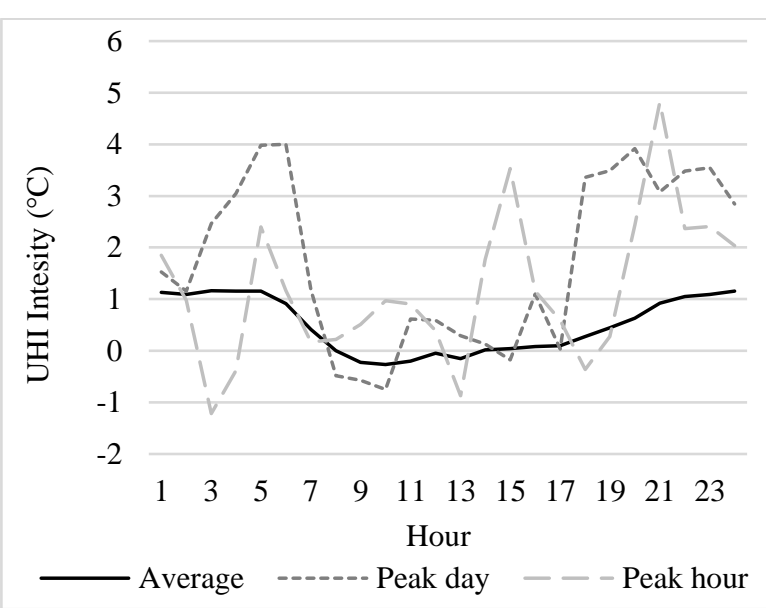

(b) UHII versus LEA rural site

Fig. 6. UHI intensity diurnal profiles for July and May-September.

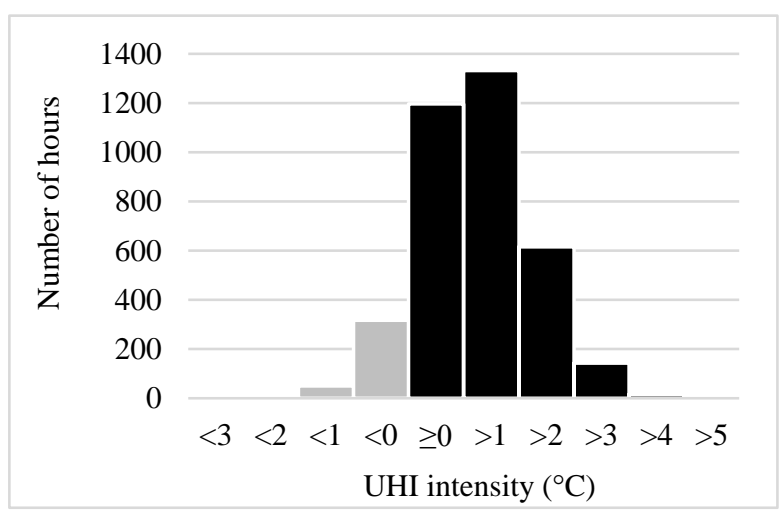

(a) UHII hours versus all rural sites

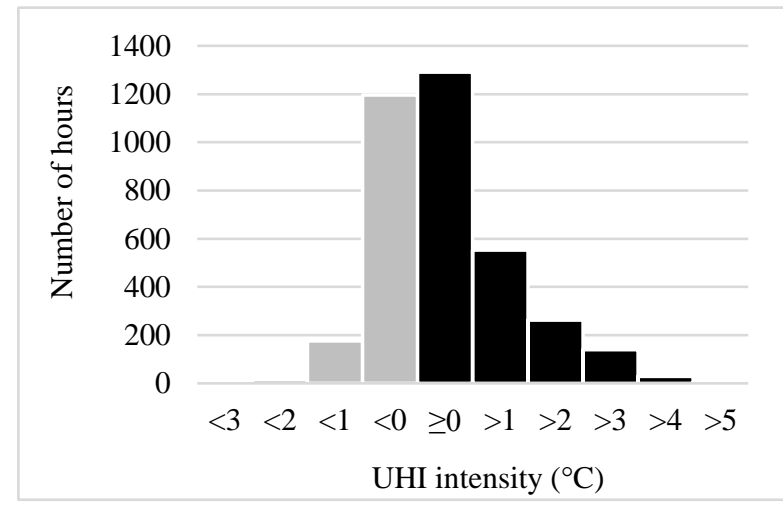

(b) UHII hours versus LEA rural site

Fig. 7. Distribution of hours within UHI intensity ranges over May-September

Analysis of the results described for the weather and UHII for Leeds, plus existing literature, indicate a relationship between lower wind speeds and increased UHII. Data visualised in Fig. 7 show the diurnal pattern of average UHII in relation to the mean daily speed for the UOL site. This supports the notion of higher UHIIs during lower wind speeds with an average UHII of $0.9^{\circ} \mathrm{C}$ when the mean daily wind speed is below 4 metres per second, compared with an average of $0.4^{\circ} \mathrm{C}$ when wind speeds are equal to or above 5 metres per second. 


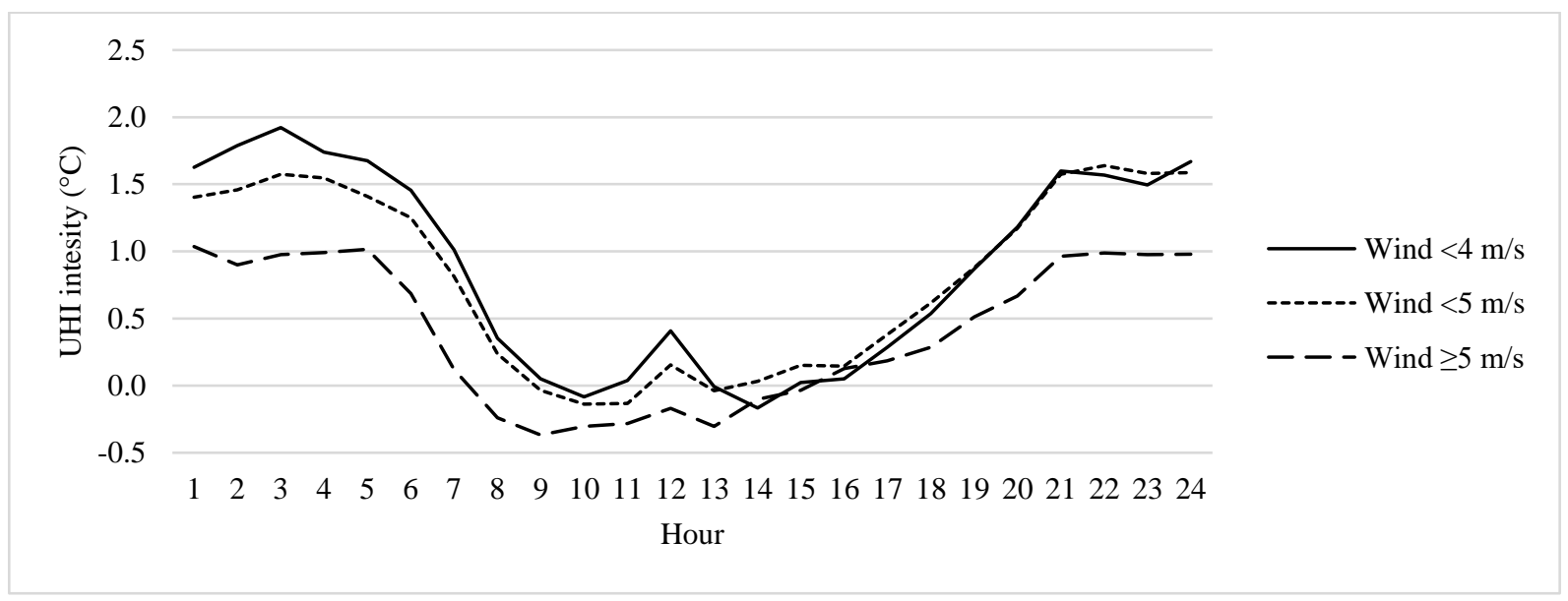

Fig. 8. Diurnal UHII profile related to mean daily wind speeds at UOL site

The average diurnal UHII profile for 2013 was compared with those from other years, to demonstrate that 2013 is representative of common conditions. The UHII profiles are shown in Fig. 9. Only measured air temperature data from the urban LBU site and the rural LBA site were available for these calculations. As already described, it is expected that the UHII values between these sites is higher than those compared with the significantly lower and less windy LEA site. The diurnal pattern is however similar for all the compared May-September periods, although the average peak intensity ranges from $2.3{ }^{\circ} \mathrm{C}$ in 2019 up to $3.6^{\circ} \mathrm{C}$ in 2017 ; peaks for all years occur during late evening. The data analysed here show that there is a relatively consistent diurnal pattern for the UHII in Leeds. The extent to which this has an impact on building energy and thermal performance is explored in the following section.

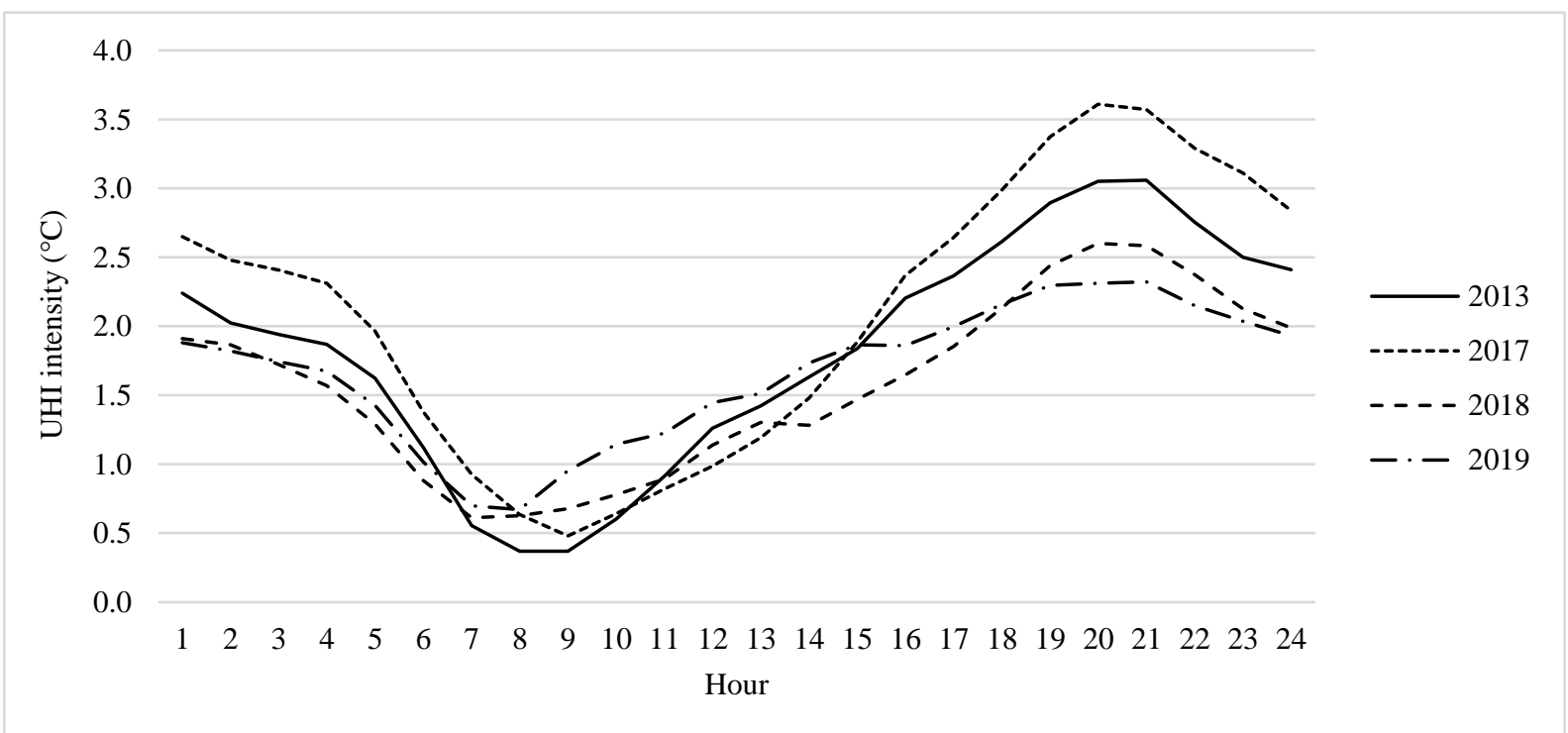

Fig. 9. Average UHI intensity diurnal profiles between urban sites and LBA site

\subsection{Building performance}

Differences in non-domestic building performance across the four case study sites are visualised in Fig. 10. These charts show the monthly energy demand for cooling. In all cases, 
consumption increases in the hotel building at both urban sites compared with both rural sites, although increases compared with the LEA site (which is used for regulatory compliance calculations) are less than those for the LBA site. The introduction of urban shading from surrounding buildings had a significant impact on performance, with consumption less than half when surrounding buildings of equal height are introduced to the model. Importantly, the proportionate difference between the urban and LEA sites is still evident, as illustrated in Fig. 11. These proportionate differences are reduced but still show the impact of the UHI. This demonstrates the importance of including the urban shading in this type of calculation wherever it is present.

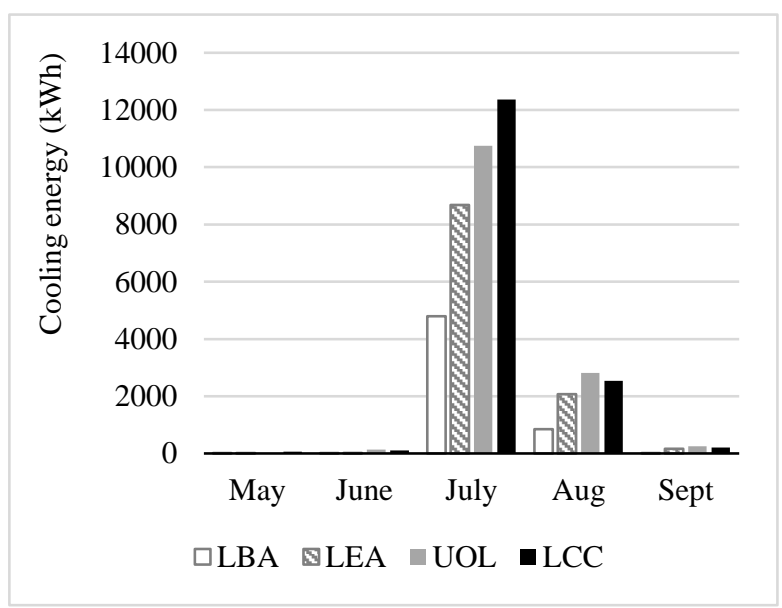

(a) Hotel cooling (no urban shading)

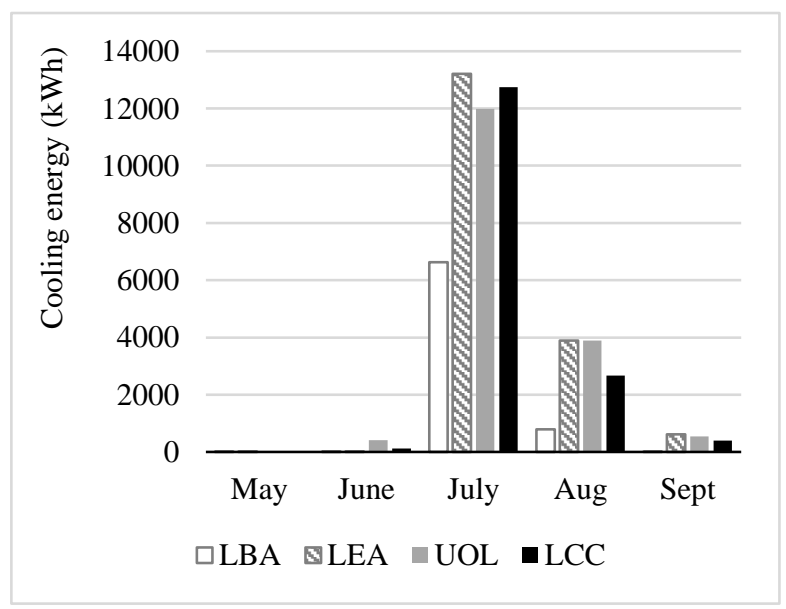

(c) Office cooling (no urban shading)

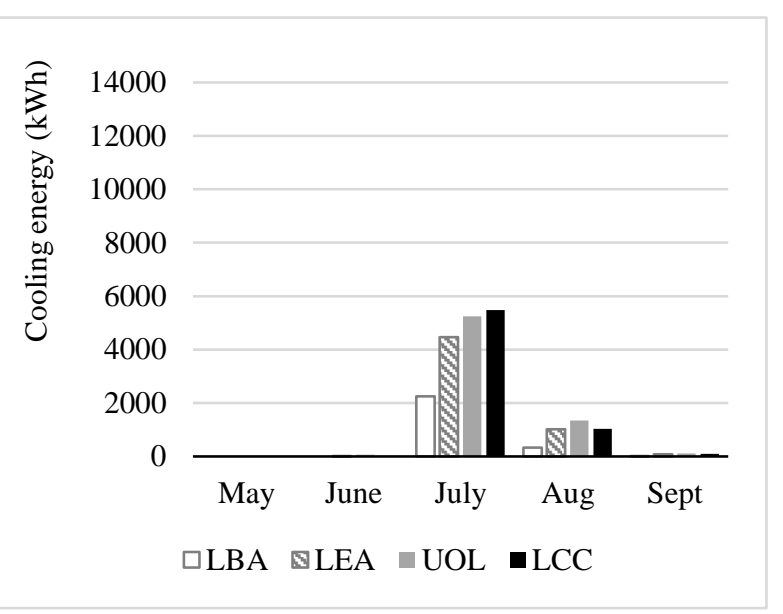

(b) Hotel cooling (with urban shading)

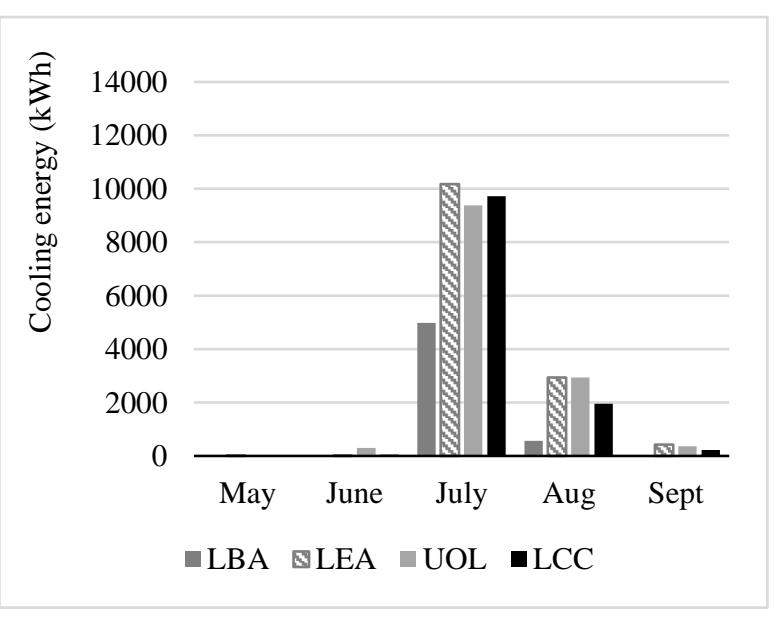

(d) Office change (no urban shading)

Fig. 10. Differences between cooling energy consumption for non-domestic buildings across the urban and rural sites.

Although the office building consumption increases when compared with LBA, it is slightly reduced when compared with the LEA site; this is due to daytime temperatures often being slightly lower at the urban sites. Introducing the urban shading for the office model has less impact on the absolute consumption values and the impact is less pronounced than that in the hotel building. Although the gross proportion of glazing is only slightly higher in the hotel than the office building, it is important to note that the proportion of glazing on the west facing façade is significantly higher at $40 \%$; this façade will be subject to direct solar gain until late 
evening as hotel occupancy begins to increase in the models with no urban shading. As mentioned in section 3, these results should not be considered definitive as, in reality, the extent of urban shading will depend upon the building location. Realistic values are likely to fall within the upper and lower range reported here dependent upon the amount of local shading. Percentage change in consumption compared with the LEA site is emphasised in Fig. 11. Absolute consumption values are reduced when urban shading is introduced but the relative change in consumption between the LEA and other sites remains evident for the hotel building and does not change significantly for the office building.

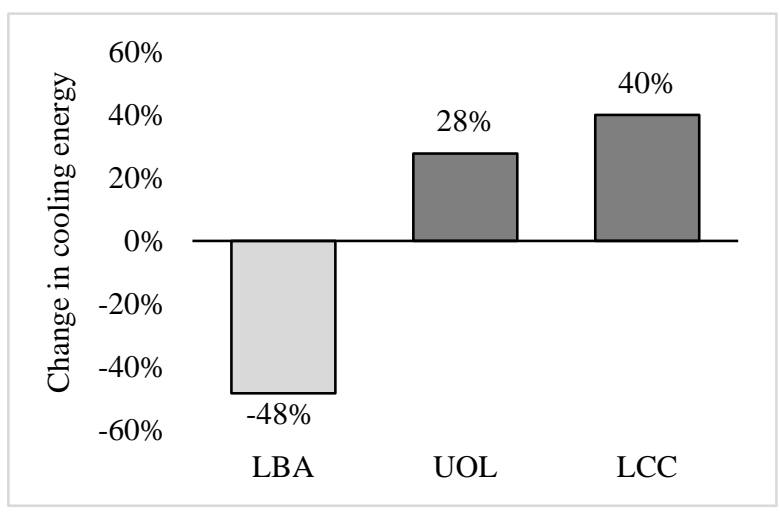

(c) Hotel change (no urban shading)

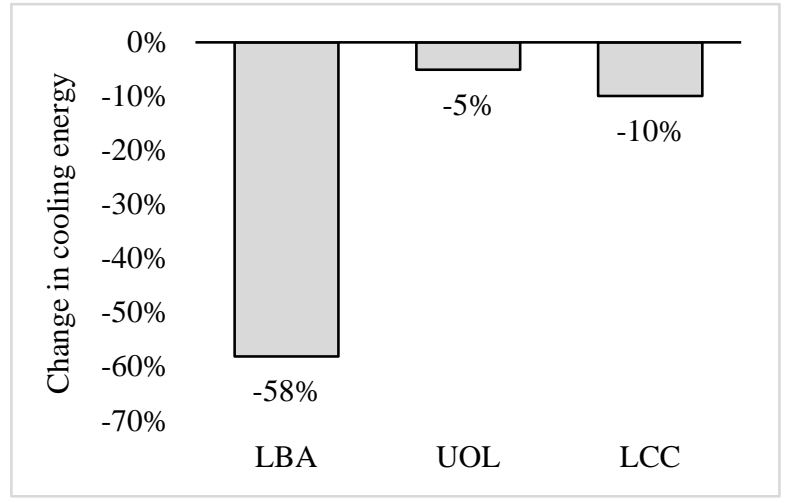

(c) Office cooling (no urban shading)

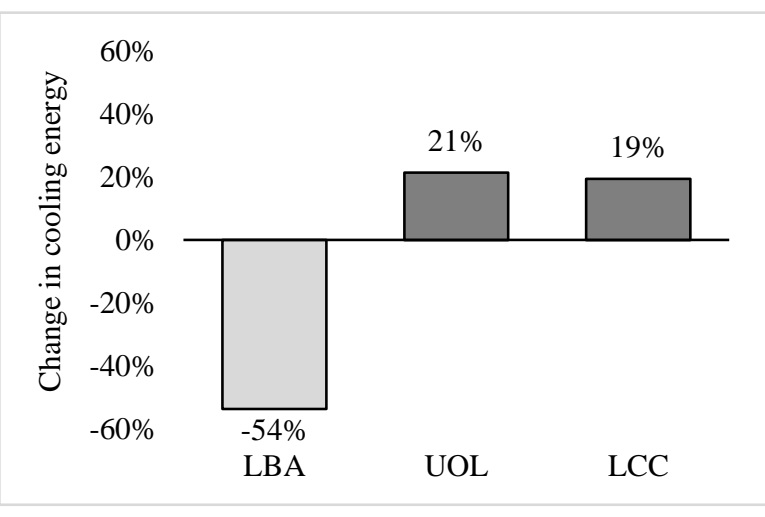

(d) Hotel change (with urban shading)

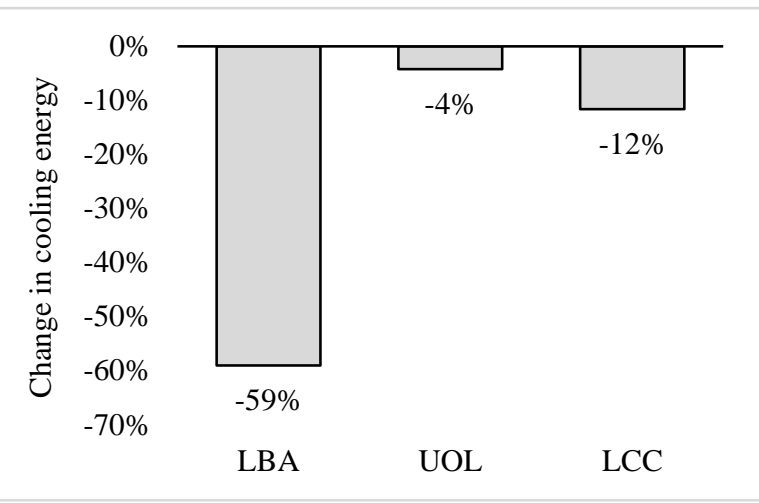

(d) Office change (with urban shading)

Fig. 11. Percentage change in consumption compared with LEA site for non-domestic buildings.

The impact of the UHII diurnal profile for Leeds on the non-domestic buildings is illustrated in Fig. 12. Again, absolute consumption is reduced when urban shading is included but the pattern of consumption remains similar, with the lag between demand in the rural and urban locations still visible in the charts. In these theoretical models, the hotel building has a 24hour cooling control profile and is therefore more susceptible to the heat island effect. In contrast, the daytime occupancy pattern of the office building means that cooling demand during this time is similar across the LEA and urban sites, although higher at all sites when compared with LBA. 


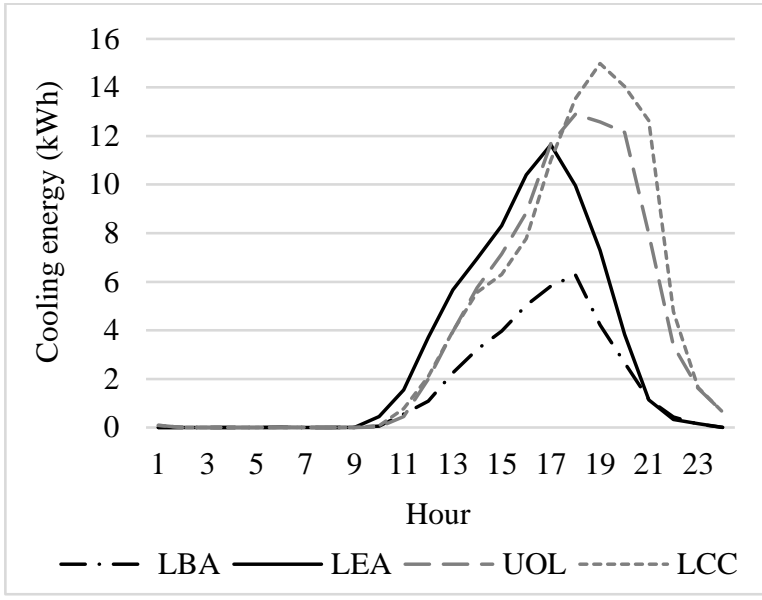

(a) Hotel (no urban shading)

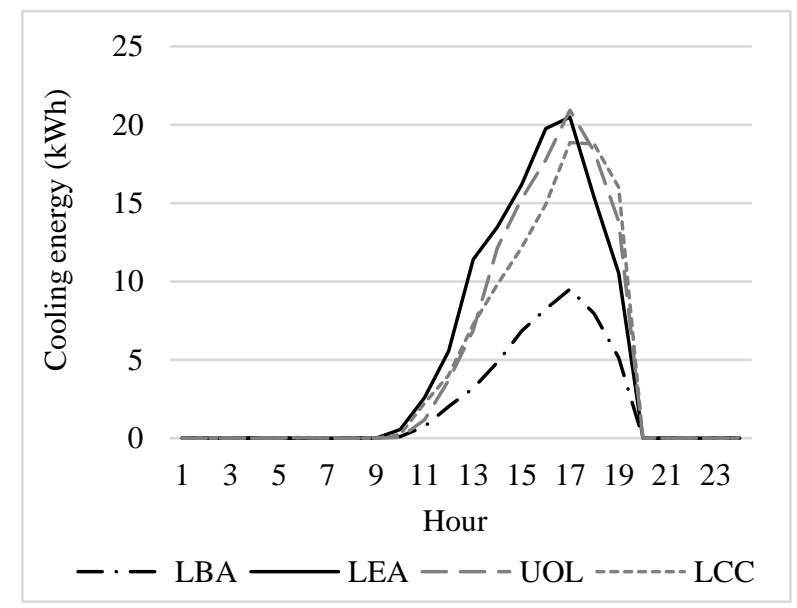

(c) Office (no urban shading)

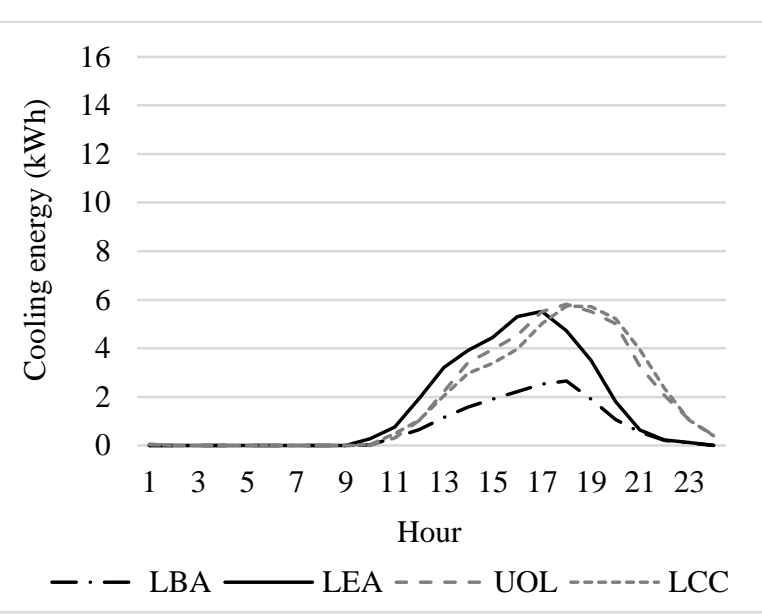

(b) Hotel (with urban shading)

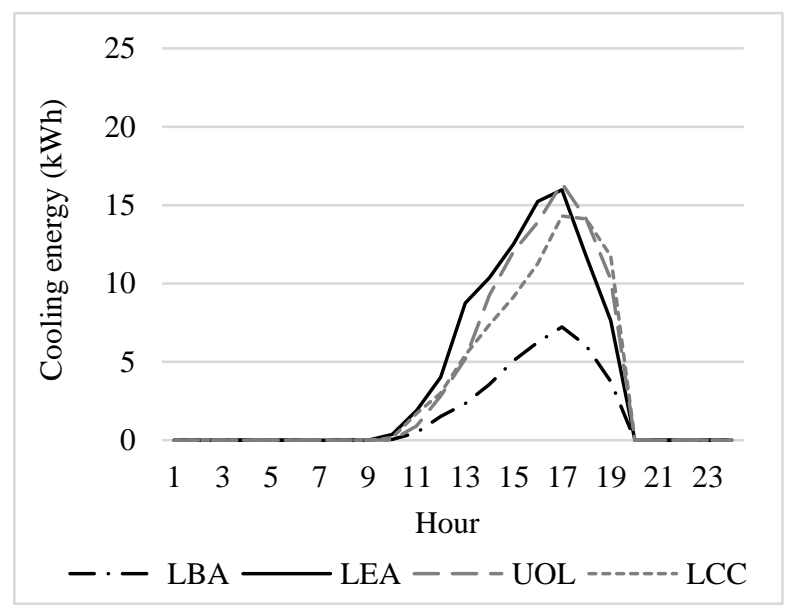

(d) Office (with urban shading)

Fig. 12. Average diurnal pattern in cooling energy consumption

In the modelled domestic examples, the importance of wind speed on natural ventilation is emphasised. The charts in Fig. 13 and 14 illustrate changes in the number of occupied hours above $25^{\circ} \mathrm{C}$ and $28{ }^{\circ} \mathrm{C}$. In the apartment building, the occupied hours above these thresholds increase slightly between the UOL and LEA sites; it is however notable that higher internal temperatures are predicted in both domestic building examples at less windy LCC site. In the terraced house example, the importance of wind speed is most evident. Despite a measurable nocturnal UHII at the UOL site, there are significantly higher wind speeds when compared with the LEA site (mean daily average of $6.2 \mathrm{~m} / \mathrm{s}$ versus $3.9 \mathrm{~m} / \mathrm{s}$ ). The importance of this can be seen in Fig. 13 where all but the living space in the UOL location experience slightly more occupied hours above the thresholds than at LEA. As with the non-domestic buildings, the introduction of urban shading has an impact on results, with a reduced the number of hours at higher temperatures. This is more pronounced in the terraced house, in particular for the south-facing lounge room which is on the ground floor of the building. 


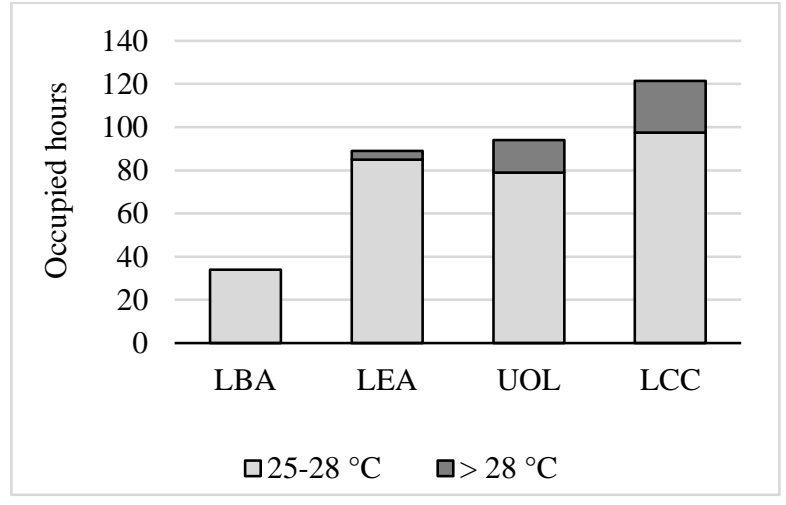

(a) Living space (no urban shading)

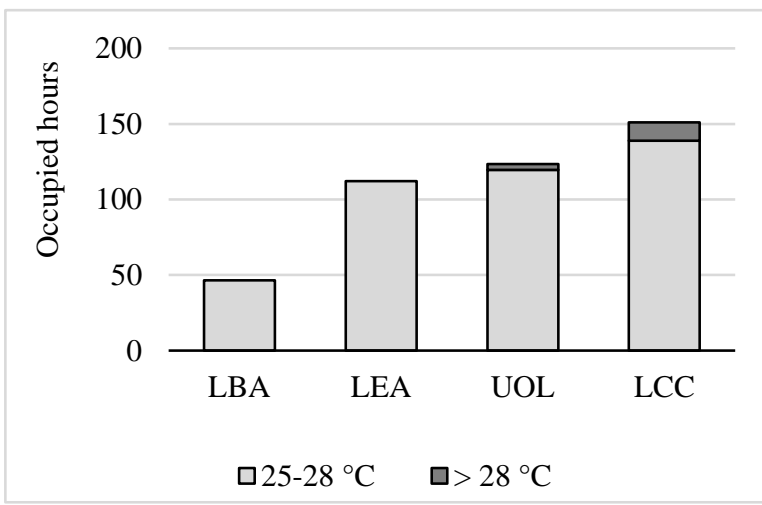

(c) Bedroom (no urban shading)

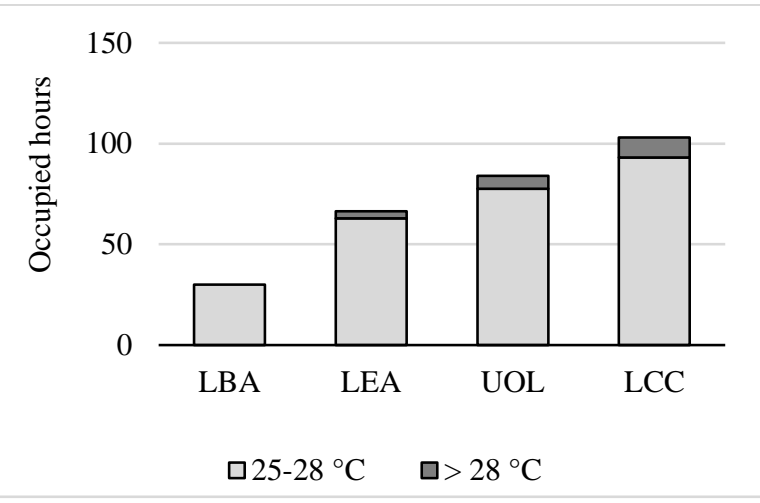

(b) Living space (with urban shading)

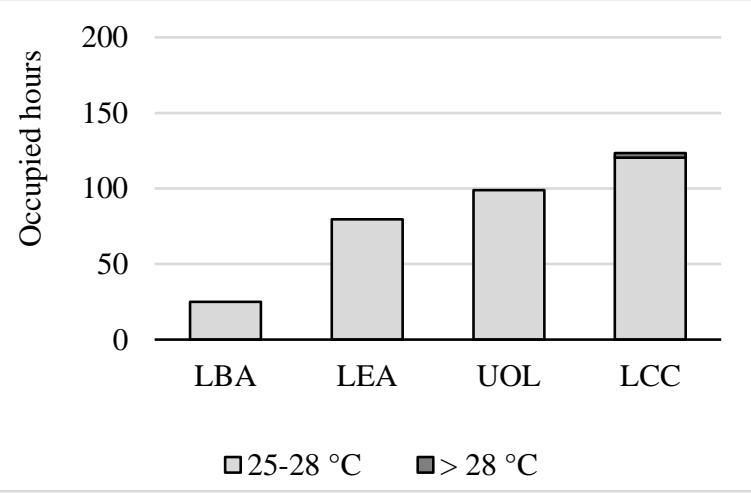

(d) Bedroom (with urban shading)

Fig. 13. Occupied hours within air temperature ranges: apartment

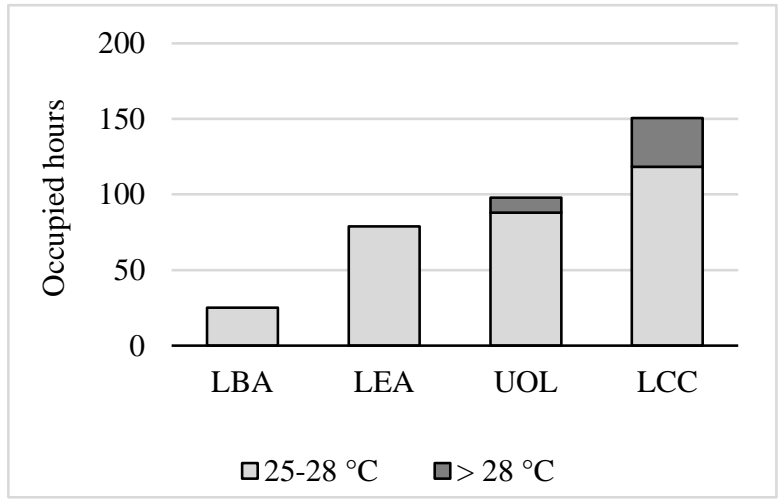

(a) Lounge (no urban shading)

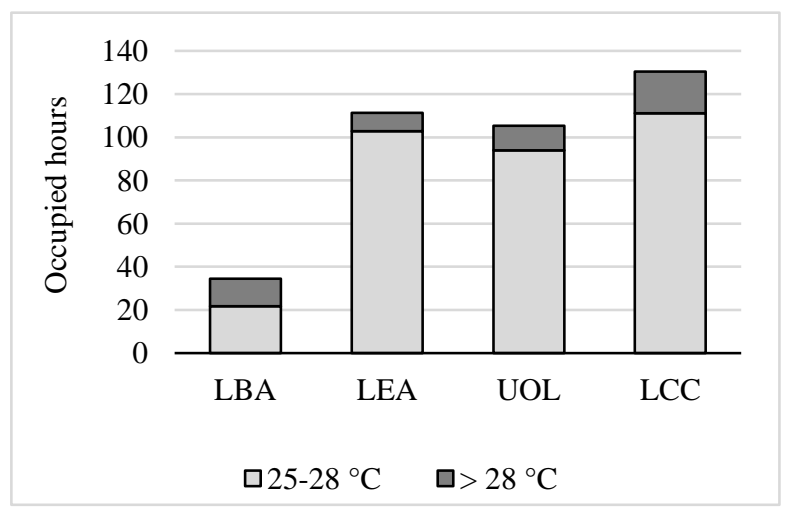

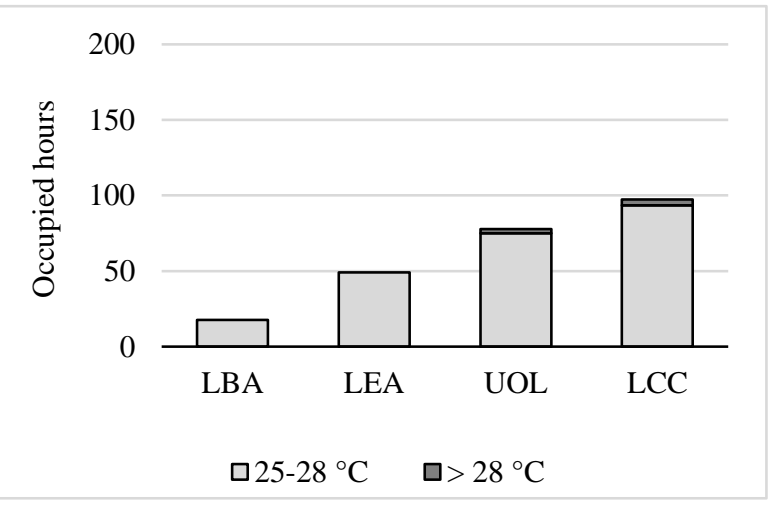

(b) Lounge (with urban shading)

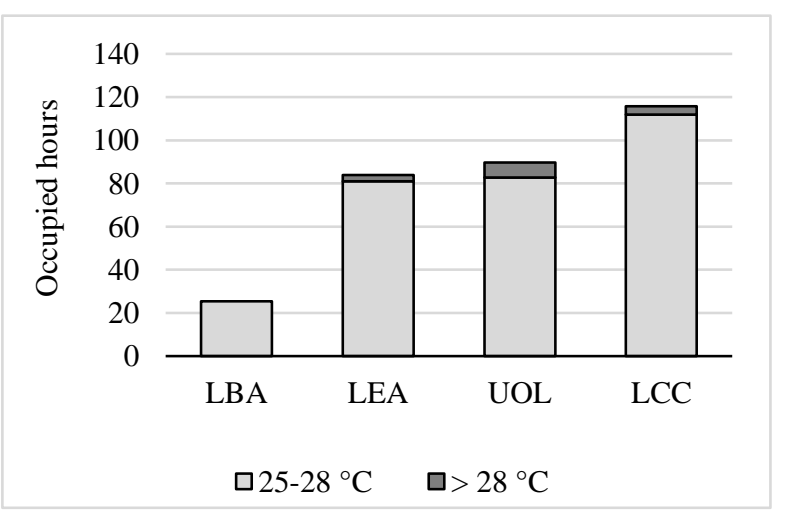


(c) Kitchen (no urban shading)

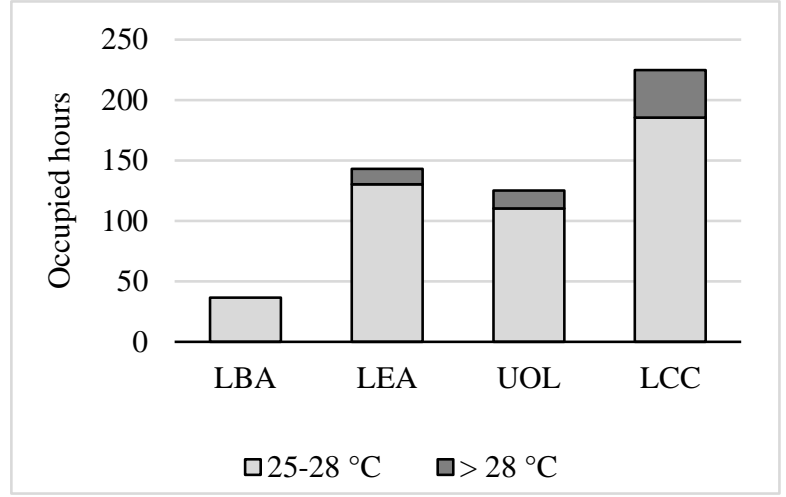

(e) Bedroom (no urban shading) (d) Kitchen (with urban shading)

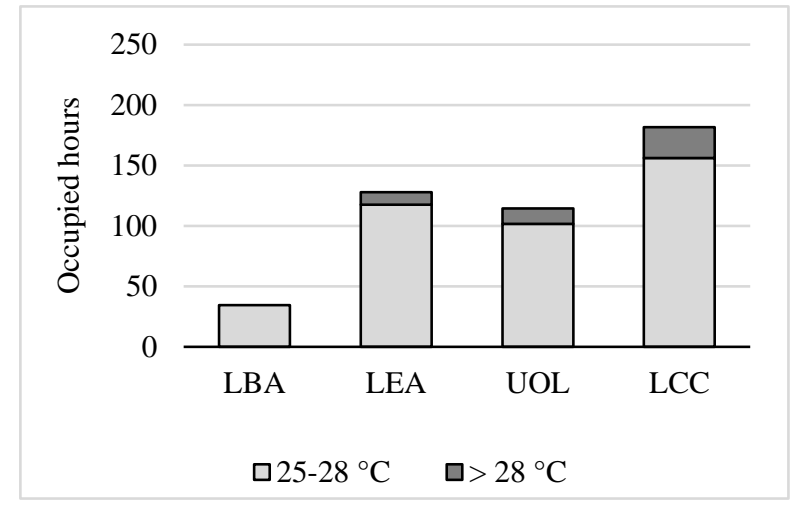

(f) Bedroom (with urban shading)

Fig. 14. Occupied hours within air temperature ranges: house

Finally, the difference between the standards of building fabric can be seen in Fig. 15, which illustrates the average diurnal internal air temperature profiles during July in the two domestic examples. The pattern of warmer temperatures in the early evening and throughout the night can be seen in both examples. However, the much better insulated apartment building does not drop below $21^{\circ} \mathrm{C}$ in any scenario whereas the terraced house cools down much more effectively at the LBA site. It is useful here to reiterate here that the dwellings are naturally ventilated, with windows assumed to be opened when internal temperatures reach $25^{\circ} \mathrm{C}$. The importance of wind to cooling is again evident, with warmer temperatures persisting at the LCC site which experiences the lowest average wind speed; this is also visible in the cooler temperatures found in the UOL example during the daytime hours. Urban shading from the surrounding buildings has a less pronounced impact on the bedroom in the apartment building than in the house. The fundamental difference being that the apartment bedroom is shaded by the balconies incorporated in the existing structure in both scenarios. The impact of the urban shading is emphasised by the south-facing bedroom in the house, with the internal air temperature accumulating at a slower rate due to the reduced direct solar gain.

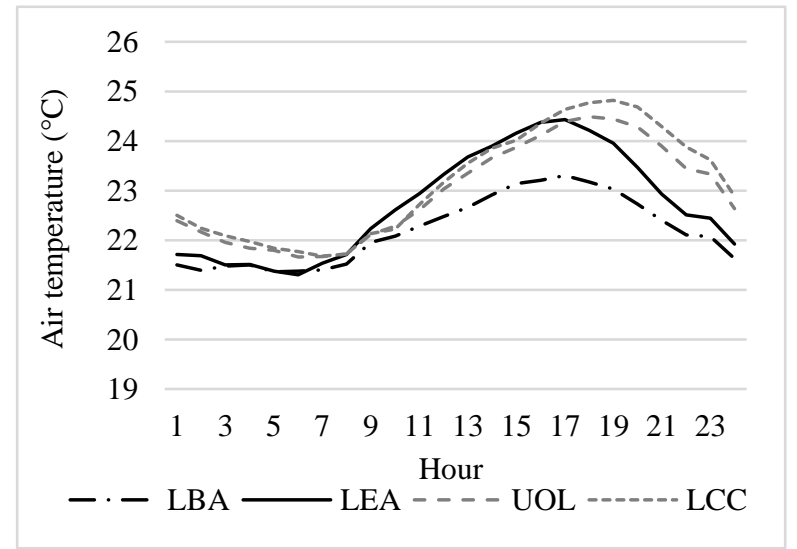

(a) Apartment (no urban shading)

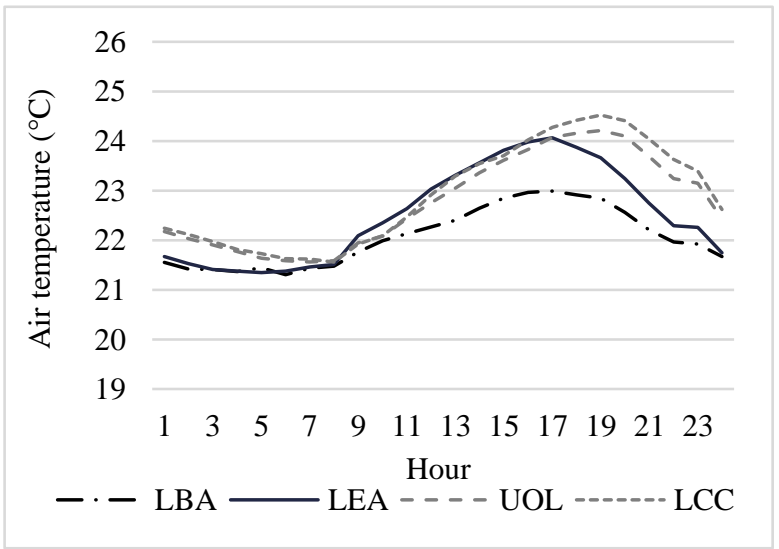

(b) Apartment (with urban shading) 


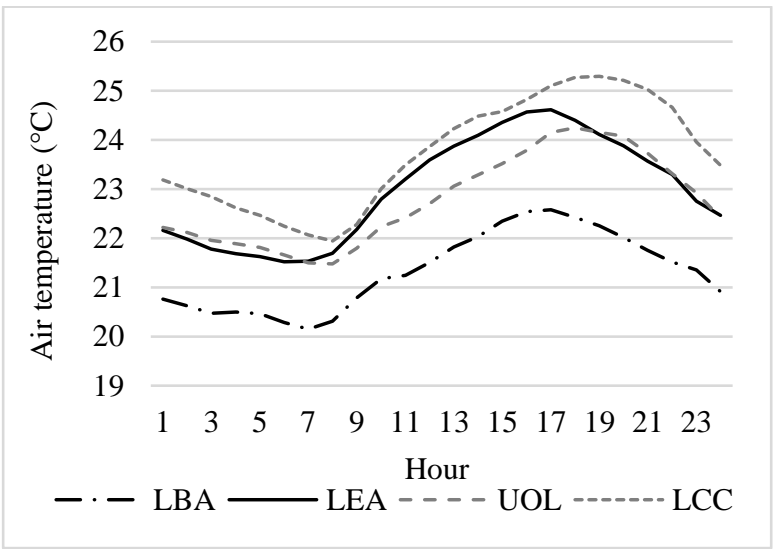

(c) House (no urban shading)

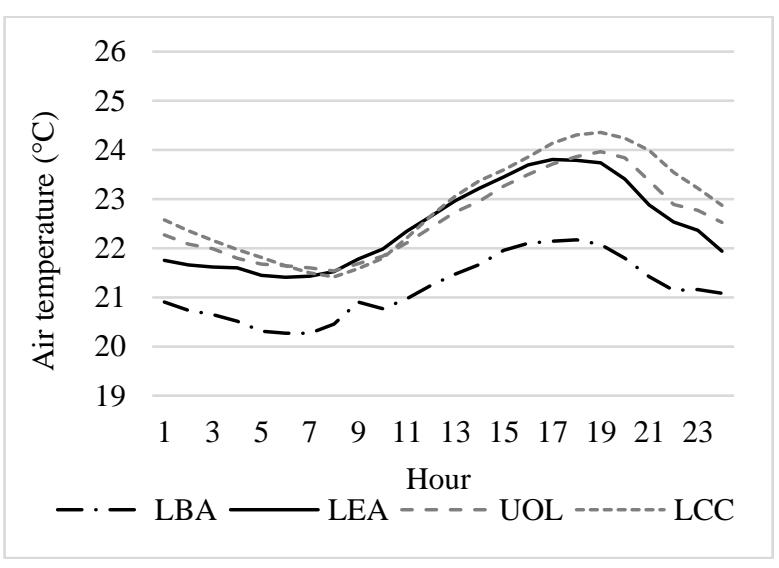

(d) House (with urban shading)

Fig. 15. Average diurnal air temperature profiles for bedrooms during July

\section{DISCUSSION}

Based upon the data analysis presented here, the UHI of Leeds is as significant as those measured in many other cities, within the UK, Europe and the rest of the world. Diurnal patterns of the UHII are also similar to those in other cities, with much higher UHII during late evening and during nocturnal hours. The topography around Leeds appears to have an observable impact on the extent of the calculated UHII. The Aire river valley traverses the city from the NorthWest to the South-East, meaning that some of the city centre is at relatively low elevations. There are significant increases in altitude in the areas to the North, North-West and West of the city and decreases to the East and South-East in particular. This emphasises the importance of understanding the topography of cities when evaluating UHII and the importance of using more than one rural reference site; the UHII is much greater between the urban sites and the LBA site to the North-West. Analysis of data suggests that this is linked not only to the increased elevation of the site, but also to the increased wind speeds.

As with other cities, the UHII in Leeds is affected by wind speed, with higher UHII during periods with less wind. This has a direct impact on building performance, and on naturally ventilation specifically. Although there is close agreement between the temperatures recorded at both urban sites, the wind speed at the UOL site was regularly higher. Increased wind speeds will aid natural ventilation which allows the domestic buildings used here to cool down more effectively. Results presented here also suggest this aids the performance of the air-cooled chillers and helps to reduce related energy consumption when compared with less windy sites.

When results for the urban sites are compared with those from the LEA site, notable impacts on performance are predicted. This is important as it is historical data from the LEA site that is used to compile the building simulation weather files used in regulatory compliance for nondomestic buildings. Results indicate this would lead to a gap between predicted and actual performance, which has relevance for building designers and operators, as this could lead to higher than expected costs. However, this is directly linked to occupied periods and results presented here show that buildings which operate during typical office hours (08:00-18:00) would have similar, if not slightly lower cooling energy consumption. Conversely, buildings with significant cooling loads outside of these hours (hotels, bars and restaurants for example), would experience increased consumption. For naturally ventilated dwellings, the UHI leads to higher temperatures from early evening and throughout the night. This suggests that the UHI 
could lead to insufficient overheating mitigation design features being included at the detriment to human thermal comfort.

Accounting for urban shading in this type of analysis is shown to be important. When no overshading is present, potential for overheating and increased energy consumption can be significantly higher than that found when urban shading is included. Although it is important to note that the proportionate impact of the UHI is still evident in models that include urban shading. In practice, this should be considered for each specific building, especially when significant over-shading may occur on the south and west façades of the building, as excessive heat gains on these elevations could exacerbate night-time overheating in the northern hemisphere. The impact of urban shading in the context of UHI in this type of temperate climate warrants further research. For instance, during the design stage, a building model incorporating extensive urban shading and a weather file that accounts for the UHI may predict a similar cooling demand for the same building at a rural, unshaded site. Furthermore, the same modelling exercise that uses traditional weather files that do not account for the UHI, could predict higher cooling demand at the unshaded rural site. This could have some important implications for a client's site selection and design appraisal, especially in normally temperate cities.

There are a number of limitations to this work. The weather data used in the building modelling calculations is based upon data from 2013 only. Ideally, further work would acquire comparable data from multiple years to validate the exercise further. There were also some limitations in the measured data used here. The most notable of these being the lack of measured direct and diffuse solar radiation, and cloud cover data. Only global radiation data was available for the urban sites and the beam factor for the LEA site was used to convert the global to the direct and diffuse values required for the building simulation weather files. Cloud cover data from the LEA site were also used for the urban sites in this study. Model sensitivity to site specific cloud cover therefore required further research. A limited number of notional buildings were used to model UHI impacts on performance. It would be useful to model the impact on a wider building stock, and, ultimately, gather measured data from operational buildings; although this would then add complexity to the comparison. The impact of the UHI on naturally ventilated nondomestic buildings is not covered in this paper either and will be explored in further work. Further work should also consider the impact of the UHI during the heating season as well.

The research presented here forms a small part of a wider research project: GIAUrban (Green Infrastructure Assets in Urban Heat Islands). A network of 20 air temperature sensors were installed during June 2019 within Leeds city centre. This is due to be extended to 80 during 2020 , with another 60 sensors being installed across the wider urban area. A range of further work is already underway and will aim to evaluate the impact of green space on the UHII and the influence of the changes in elevation found across Leeds. Another aspect of this work aims to use machine learning techniques and artificial neural network analysis to predict the UHII in Leeds and other cities using multiple weather variables. This will then be used to develop weather files for future climate scenarios in Leeds and in other heating dominated climates.

The work presented here has implications for both policy and practice. Results show that developing a central Leeds weather file for use in regulatory compliance calculations could help to avoid unexpected energy consumption and overheating. This work, along with other studies across the UK and Europe, suggest that this type of weather file that accounts for the UHI should be mandated for all urban developments to provide more accurate prediction of building performance. Beyond their use in regulatory compliance calculations, UHI weather files would allow for practitioners to better optimize the form and function of their future designs, for 
example including additional shading that may not appear to be necessary when design are modelled using the existing regional weather files.

\section{CONCLUSION}

Consistent differences between temperatures within Leeds city centre and surrounding rural sites have been identified in this work. The intensity of the Leeds UHI has been calculated, with a peak hourly value of $5.9{ }^{\circ} \mathrm{C}$ during 2013 , and an average peak of $2.3{ }^{\circ} \mathrm{C}$ occurring at 20:00. The diurnal profile of the Leeds UHII has been characterized as a predominantly nocturnal phenomenon, with higher temperatures from early evening and throughout the night. Topographic features of a city can have an impact on the calculated UHII, and the importance of understanding this in analysis has been emphasised in this work. When calculating the daily mean UHII for Leeds, the rural reference site with a relatively high elevation returns a value of $1.2^{\circ} \mathrm{C}$, whereas the mean value when compared to the site with a relatively low elevation is $0.6{ }^{\circ} \mathrm{C}$. Modelling of building performance confirms that the Leeds UHI will have the greatest impact on buildings that have a night-time cooling requirement, either through increased chiller energy consumption, or increased internal air temperatures in naturally ventilated buildings. Although this could lead to gaps in performance, this is only likely to manifest in buildings that are occupied overnight.

\section{ACKNOWLEDGEMENTS}

Part of this work was funded via the Innovate UK project: Green Infrastructure Assets in Urban Heat Islands (project reference 104014). This project is led by VRM Tech Ltd who have supported this work along with the University of Hull who are the third consortium member. Thanks are also due to Richard Crowther of Leeds City Council who provided the historical weather data for the Knowsthorpe Gate site.

\section{REFERENCES}

[1] S. Yamashita, K. Sekine, Some studies on the earth's surface conditions relating to the urban heat island, Energy and Buildings, 15 (C) (1990) 279-288.

[2] H. Taha, Urban climates and heat islands: Albedo, evapotranspiration, and anthropogenic heat, Energy and Buildings, 25 (2) (1997) 99-103.

[3] H. Akbari, D. Kolokotsa, Three decades of urban heat islands and mitigation technologies research, Energy and Buildings, 133 (2016) 834-852.

[4] T.R. Oke, The distinction between canopy and boundary-layer urban heat Islands, Atmosphere, 14 (4) (1976) 268-277.

[5] I.D. Stewart, A systematic review and scientific critique of methodology in modern urban heat island literature, International Journal of Climatology, 31 (2) (2011) 200-217.

[6] P.A. Mirzaei, F. Haghighat, Approaches to study Urban Heat Island - Abilities and limitations, Building and Environment, 45 (10) (2010) 2192-2201.

[7] G.J. Levermore, J.B. Parkinson, P.J. Laycock, S. Lindley, The urban heat island in manchester 19962011, Building Services Engineering Research and Technology, 36 (3) (2015) 343-356.

[8] C.P. Skelhorn, G. Levermore, S.J. Lindley, Impacts on cooling energy consumption due to the UHI and vegetation changes in Manchester, UK, Energy and Buildings, 122 (2016) 150-159.

[9] C. Demanuele, A. Mavrogianni, M. Davies, M. Kolokotroni, I. Rajapaksha, Using localised weather files to assess overheating in naturally ventilated offices within London's urban heat island, Building Services Engineering Research and Technology, 33 (4) (2012) 351-369. 
[10] E. Oikonomou, M. Davies, A. Mavrogianni, P. Biddulph, P. Wilkinson, M. Kolokotroni, Modelling the relative importance of the urban heat island and the thermal quality of dwellings for overheating in London, Building and Environment, 57 (2012) 223-238.

[11] J. Taylor, P. Wilkinson, R. Picetti, P. Symonds, C. Heaviside, H.L. Macintyre, M. Davies, A. Mavrogianni, E. Hutchinson, Comparison of built environment adaptations to heat exposure and mortality during hot weather, West Midlands region, UK, Environment International, (2017).

[12] M. Herrera, S. Natarajan, D.A. Coley, T. Kershaw, A.P. Ramallo-González, M. Eames, D. Fosas, M. Wood, A review of current and future weather data for building simulation, Building Services Engineering Research and Technology, 38 (5) (2017) 602-627.

[13] CIBSE, CIBSE Weather Data Sets, in, CIBSE, London, 2016.

[14] C. Bonfigli, M. Chorafa, S. Diamond, C. Eliades, A. Mylona, B. Taylor, D. Virk, TM59: Design methodology for the assessment of overheating risk in homes., in: K. Butcher (Ed.), CIBSE, London, 2017.

[15] M. Eames, T. Kershaw, D. Coley, On the creation of future probabilistic design weather years from UKCP09, Building Services Engineering Research and Technology, 32 (2) (2011) 127-142.

[16] M. Eames, T. Kershaw, D. Coley, The appropriate spatial resolution of future weather files for building simulation, Journal of Building Performance Simulation, 5 (6) (2012) 347-358.

[17] M. Kolokotroni, X. Ren, M. Davies, A. Mavrogianni, London's urban heat island: Impact on current and future energy consumption in office buildings, Energy and Buildings, 47 (2012) 302-311.

[18] J. Hacker, S. Belcher, A. White, TM49: Design Summer Years for London, in, CIBSE, London, 2015.

[19] HM Government, UK Building Regulations. Part L2A: Conservation of Fuel and Power in Buildings Other than Dwellings in, RIBA Publishing Ltd, London, 2014.

[20] HM Government, UK Building Regulations. Part L2B: Conservation of fuel and power in existing buildings other than dwellings in, RIBA Publishing Ltd, London, 2014.

[21] A. Mohajerani, J. Bakaric, T. Jeffrey-Bailey, The urban heat island effect, its causes, and mitigation, with reference to the thermal properties of asphalt concrete, Journal of Environmental Management, 197 (2017) 522-538.

[22] H. Rosatto, G.F. Botta, A.T. Becerra, H. Tardito, M. Leveratto, Climate change difficulties in the Buenos Aires city contribution of green roofs in regulating the thermal change, Revista de la Facultad de Ciencias Agrarias, 48 (1) (2016) 197-209.

[23] J. Martin-Vide, P. Sarricolea, M.C. Moreno-García, On the definition of urban heat island intensity: The "rural" reference, Frontiers in Earth Science, 3 (2015).

[24] T.R. Oke, Classics in physical geography revisited: Sundborg, Å. 1951: Climatological studies in Uppsala with special regard to the temperature conditions in the urban area. Geographica 22, Progress in Physical Geography, 19 (1) (1995) 107-113.

[25] L. Romero Rodríguez, J. Sánchez Ramos, F.J. Sánchez de la Flor, S. Álvarez Domínguez, Analyzing the urban heat Island: Comprehensive methodology for data gathering and optimal design of mobile transects, Sustainable Cities and Society, 55 (2020).

[26] A. Mahdavi, K. Kiesel, M. Vuckovic, Methodologies for UHI analysis: Urban heat Island phenomenon and related mitigation measures in central Europe, in: Counteracting Urban Heat Island Effects in a Global Climate Change Scenario, 2016, pp. 71-91.

[27] F. Despini, C. Ferrari, A. Bigi, A. Libbra, S. Teggi, A. Muscio, G. Ghermandi, Correlation between remote sensing data and ground based measurements for solar reflectance retrieving, Energy and Buildings, 114 (2016) 227-233. 
[28] Y. Cui, D. Yan, T. Hong, J. Ma, Temporal and spatial characteristics of the urban heat island in Beijing and the impact on building design and energy performance, Energy, 130 (2017) 286-297.

[29] K.J. Doick, A. Peace, T.R. Hutchings, The role of one large greenspace in mitigating London's nocturnal urban heat island, Science of The Total Environment, 493 (2014) 662-671.

[30] S. Kawashima, T. Ishida, M. Minomura, T. Miwa, Relations between surface temperature and air temperature on a local scale during winter nights, Journal of Applied Meteorology, 39 (9) (2000) 1570 1579.

[31] P. Dobrovolný, L. Krahula, The spatial variability of air temperature and nocturnal urban heat island intensity in the city of Brno, Czech Republic, Moravian Geographical Reports, 23 (3) (2015) 8-16.

[32] R. Giridharan, S.S.Y. Lau, S. Ganesan, Nocturnal heat island effect in urban residential developments of Hong Kong, Energy and Buildings, 37 (9) (2005) 964-971.

[33] D. Zhou, S. Zhao, S. Liu, L. Zhang, C. Zhu, Surface urban heat island in China's 32 major cities: Spatial patterns and drivers, Remote Sensing of Environment, 152 (2014) 51-61.

[34] P. Zhang, M.L. Imhoff, R.E. Wolfe, L. Bounoua, Characterizing urban heat islands of global settlements using MODIS and nighttime lights products, Canadian Journal of Remote Sensing, 36 (3) (2010) 185-196.

[35] J. Zhang, Y. Hou, G. Li, H. Van, L. Yang, F. Yao, The diurnal and seasonal characteristics of urban heat island variation in Beijing city and surrounding areas and impact factors based on remote sensing satellite data, Science in China, Series D: Earth Sciences, 48 (SUPPL.2) (2005) 220-229.

[36] Y. Kamarianakis, X. Li, B.L. Turner Ii, A.J. Brazel, On the effects of landscape configuration on summer diurnal temperatures in urban residential areas: application in Phoenix, AZ, Frontiers of Earth Science, (2017) 1-19.

[37] T.R. Oke, The energetic basis of the urban heat island, Quarterly Journal of the Royal Meteorological Society, 108 (455) (1982) 1-24.

[38] G. Levermore, J. Parkinson, The urban heat island of London, an empirical model, Building Services Engineering Research and Technology, 40 (3) (2019) 290-295.

[39] J. Bernard, M. Musy, I. Calmet, E. Bocher, P. Keravec, Urban heat island temporal and spatial variations: Empirical modeling from geographical and meteorological data, Building and Environment, 125 (2017) 423-438.

[40] O. Buchin, M.T. Hoelscher, F. Meier, T. Nehls, F. Ziegler, Evaluation of the health-risk reduction potential of countermeasures to urban heat islands, Energy and Buildings, 114 (2016) 27-37.

[41] M. Hendel, K. Azos-Diaz, B. Tremeac, Behavioral adaptation to heat-related health risks in cities, Energy and Buildings, 152 (2017) 823-829.

[42] A. Mavrogianni, M. Davies, M. Batty, S.E. Belcher, S.I. Bohnenstengel, D. Carruthers, Z. Chalabi, B. Croxford, C. Demanuele, S. Evans, R. Giridharan, J.N. Hacker, I. Hamilton, C. Hogg, J. Hunt, M. Kolokotroni, C. Martin, J. Milner, I. Rajapaksha, I. Ridley, J.P. Steadman, J. Stocker, P. Wilkinson, Z. Ye, The comfort, energy and health implications of London's urban heat island, Building Services Engineering Research and Technology, 32 (1) (2011) 35-52.

[43] C.R. O'Lenick, O.V. Wilhelmi, R. Michael, M.H. Hayden, A. Baniassadi, C. Wiedinmyer, A.J. Monaghan, P.J. Crank, D.J. Sailor, Urban heat and air pollution: A framework for integrating population vulnerability and indoor exposure in health risk analyses, Science of the Total Environment, 660 (2019) 715-723.

[44] K. Jenkins, J. Hall, V. Glenis, C. Kilsby, M. McCarthy, C. Goodess, D. Smith, N. Malleson, M. Birkin, Probabilistic spatial risk assessment of heat impacts and adaptations for London, Climatic Change, 124 (1) (2014) 105-117.

[45] T. Li, R.M. Horton, P.L. Kinney, Projections of seasonal patterns in temperature- related deaths for Manhattan, New York, Nature Climate Change, 3 (8) (2013) 717-721. 
[46] J. Wu, Y. Zhou, Y. Gao, S. Fu Joshua, A. Johnson Brent, C. Huang, Y.-M. Kim, Y. Liu, Estimation and Uncertainty Analysis of Impacts of Future Heat Waves on Mortality in the Eastern United States, Environmental Health Perspectives, 122 (1) (2014) 10-16.

[47] S. Grimmond, Urbanization and global environmental change: Local effects of urban warming, Geographical Journal, 173 (1) (2007) 83-88.

[48] J. Yang, Z.H. Wang, K.E. Kaloush, Environmental impacts of reflective materials: Is high albedo a 'silver bullet' for mitigating urban heat island?, Renewable and Sustainable Energy Reviews, 47 (2015) 830-843.

[49] R. Giridharan, M. Kolokotroni, Urban heat island characteristics in London during winter, Solar Energy, 83 (9) (2009) 1668-1682.

[50] C. Guattari, L. Evangelisti, C.A. Balaras, On the assessment of urban heat island phenomenon and its effects on building energy performance: A case study of Rome (Italy), Energy and Buildings, 158 (2018) 605-615.

[51] S.R. Gaffin, C. Rosenzweig, R. Khanbilvardi, L. Parshall, S. Mahani, H. Glickman, R. Goldberg, R. Blake, R.B. Slosberg, D. Hillel, Variations in New York city's urban heat island strength over time and space, Theoretical and Applied Climatology, 94 (1-2) (2008) 1-11.

[52] F. Yang, S.S.Y. Lau, F. Qian, Summertime heat island intensities in three high-rise housing quarters in inner-city Shanghai China: Building layout, density and greenery, Building and Environment, 45 (1) (2010) 115-134.

[53] M. Santamouris, Heat island research in Europe: The state of the art, Advances in Building Energy Research, 1 (1) (2007) 123-150.

[54] G. Levermore, J. Parkinson, The Manchester urban heat island and adjustments for The Chartered Institution of Building Services Engineer calculations, Building Services Engineering Research and Technology, 37 (2) (2016) 128-135.

[55] M. Kolokotroni, I. Giannitsaris, R. Watkins, The effect of the London urban heat island on building summer cooling demand and night ventilation strategies, Solar Energy, 80 (4) (2006) 383-392.

[56] R. Watkins, J. Palmer, M. Kolokotroni, P. Littlefair, The London heat island: Results from summertime monitoring, Building Services Engineering Research and Technology, 23 (2) (2002) 97 106.

[57] R. Watkins, J. Palmer, M. Kolokotroni, P. Littlefair, The balance of the annual heating and cooling demand within the London urban heat island, Building Services Engineering Research and Technology, 23 (4) (2002) 207-213.

[58] J.A. Azevedo, L. Chapman, C.L. Muller, Quantifying the daytime and night-time urban heat Island in Birmingham, UK: A comparison of satellite derived land surface temperature and high resolution air temperature observations, Remote Sensing, 8 (2) (2016).

[59] C.J. Tomlinson, T. Prieto-Lopez, R. Bassett, L. Chapman, X.M. Cai, J.E. Thornes, C.J. Baker, Showcasing urban heat island work in Birmingham - Measuring, monitoring, modelling and more, Weather, 68 (2) (2013) 44-49.

[60] M. Santamouris, C. Cartalis, A. Synnefa, D. Kolokotsa, On the impact of urban heat island and global warming on the power demand and electricity consumption of buildings - A review, Energy and Buildings, 98 (2015) 119-124.

[61] S.E. Lee, G.J. Levermore, Simulating urban heat island effects with climate change on a Manchester house, Building Services Engineering Research and Technology, 34 (2) (2013) 203-221.

[62] R. Gupta, M. Gregg, K. Williams, Cooling the UK housing stock post-2050s, Building Services Engineering Research and Technology, 36 (2) (2015) 196-220. 
[63] J. Taylor, M. Davies, A. Mavrogianni, Z. Chalabi, P. Biddulph, E. Oikonomou, P. Das, B. Jones, The relative importance of input weather data for indoor overheating risk assessment in dwellings, Building and Environment, 76 (2014) 81-91.

[64] S. Tsoka, K. Tolika, T. Theodosiou, K. Tsikaloudaki, D. Bikas, A method to account for the urban microclimate on the creation of 'typical weather year' datasets for building energy simulation, using stochastically generated data, Energy and Buildings, 165 (2018) 270-283.

[65] M.G.M. Van Der Heijden, B. Blocken, J.L.M. Hensen, Towards the integration of the urban heat island in building energy simulations, in: Proceedings of BS 2013: 13th Conference of the International Building Performance Simulation Association, 2013, pp. 1006-1013.

[66] T. Kershaw, M. Sanderson, D. Coley, M. Eames, Estimation of the urban heat island for UK climate change projections, Building Services Engineering Research and Technology, 31 (3) (2010) 251-263.

[67] Met Office, July 2013 heat wave, (no date).

[68] S.I. Bohnenstengel, S. Evans, P.A. Clark, S.E. Belcher, Simulations of the London urban heat island, Quarterly Journal of the Royal Meteorological Society, 137 (659) (2011) 1625-1640.

[69] D. Virk, M. Eames, CIBSE weather files 2016 release: Technical briefing and testing, in, CIBSE, London, 2016.

[70] White Box Technologies, White Box Technologies: Weather data for energy calculations, in, White Box Technologies Inc., Moraga, 2020.

[71] HM Government, National Calculation Methodology (NCM) modelling guide (for building other than dwellings in England and Wales), in, BRE Ltd, London, 2013.

[72] X. Shi, B. Si, J. Zhao, Z. Tian, C. Wang, X. Jin, X. Zhou, Magnitude, causes, and solutions of the performance gap of buildings: A review, Sustainability (Switzerland), 11 (3) (2019).

[73] National Oceanic and Atmospheric Administration, National Centers for Environmental Information, in, National Oceanic and Atmospheric Administration, Asheville, 2020.

[74] DesignBuilder Software Ltd, DesignBuilder Version 6.0.1.019, in, DesignBuilder Software Ltd, Stroud, UK, 2018. 